\title{
2 Angelologie. Kulturhistorische Kontroversen um die Engel
}

Warum sollte man sich mit Angelologie beschäftigen, wenn man etwas über Engel in der Moderne erfahren will, einer Zeit also, in der Lehren von den Engeln keine besondere Geltung mehr beanspruchen können? Mit der zunehmenden Loslösung der Engel aus dem Korsett theologischer Dogmatik, der die Angelologie zuzurechnen ist, werden ihre vielen Potenzen frei für kreative Adaptionen. Allerdings hängen, wie eingangs skizziert, die zunehmende Irrelevanz der Engel in der Theologie und ihre wachsende Bedeutung in weltlichen Diskursen zusammen. Daher beschäftigt sich diese Studie zu modernen Angelophanien zunächst mit den biblischen Fundamenten und mehr noch mit den biblischen Leerstellen. Denn die ausufernden angelologischen Debatten in der Spätantike und der Scholastik lassen sich als Reaktion auf fehlende Informationen und Unstimmigkeiten in der Bibel verstehen; sie sind Ausdruck des Bemühens, Konsistenz zu schaffen.

Die in den Angelologien begründeten Annahmen über Funktionen und Beschaffenheit der Engel prägten deren Rezeption bis ins 20. Jahrhundert, ohne dass sich ihre dortigen Adaptionen in der Weiterführung vormoderner Debatten erschöpften. Viele der intensiv diskutierten angelologischen Fragen sind im 20. Jahrhundert obsolet, weil die Maßgaben des weltanschaulichen Kontextes fehlen, die die Abfassung der vormodernen Angelologien prägten. Während die angelischen Unstimmigkeiten bei der Konsolidierung des christlichen Glaubens eingehegt und so begründet werden mussten, dass sie keine Bedrohung für das Axiom der Allmacht und Weisheit Gottes darstellten, sind es im 20. Jahrhundert gerade diese Unstimmigkeiten, die faszinieren und sich als besonders anschlussfähig für Anverwandlungen im Kontext spezifisch moderner Problemstellungen erweisen. Dass die Faszination der Engel bis heute anhält, hängt, so die These dieses Kapitels, mit ihrer ästhetisch vermittelten Spannung zwischen Hierarchie und Umsturz zusammen, mit der die Angelologien fertigwerden mussten. Gerade in ihrer Inkommensurabilität und ambivalenten Stellung zwischen Ordnung und Ordnungsbedrohung, Reinheit und Hybridität, Tugend und Umsturz sowie Schönheit und Monstrosität liegt die spezifische Modernität der Engel. Während dadurch für ein monotheistisches Weltbild auf vielen Ebenen Spannungspotential entstand, bieten diese Eigenheiten des Engels Anschlusspunkte für die Reflexion und Darstellung genuin moderner Fragen. 


\subsection{Die Ordnung der Engel als bürokratisches Chaos}

Wo sind Engel anzutreffen? Gibt es so etwas wie einen spezifisch angelischen Raum? Die Verortung von Engeln ist schwierig, da sie nicht an die Kategorie des Raums gebunden sind (illocalitas). Dennoch bezieht sich „ihr Sein und Wirken in der Art auf ein gewisses Wo“1, wie August Twesten im 19. Jahrhundert resümiert. Die vorsichtige Formulierung zeigt, wie heikel es ist, die Engel einfach unverortet zu lassen. Denn in einem monotheistischen Glaubenssystem darf die angelische Losgelöstheit im Gegensatz zur göttlichen keine absolute sein. Aus dem Bedürfnis, dem diffusen Raum der Engel eine klare Form zu geben, speisen sich die ausgefeilten angelologischen Schriften, die darauf abzielen, das Kollektiv der Engel sinnvoll zu strukturieren. Zahlenmäßige Bestimmungen wie die bei Daniel genannten „[t]ausendmal Tausende [...] und zehntausendmal Zehntausende“ (Dan 7,10 ) beziehungsweise die „zehntausendmal zehntausend und vieltausendmal tausend" (Offb 5,11) in der Johannesoffenbarung suggerieren mathematische Genauigkeit und lassen gleichzeitig vermuten, dass es sich bei Engeln um eine letztlich mathematisch nicht einholbare Pluralität handelt. Thomas von Aquin spricht daher von einer „transcendente[n] Vielheit“2. Auch die individuelle Bestimmbarkeit einzelner Engels scheint fragwürdig. So zeigt Johann Evangelist Hafner am Beispiel der Wendung von dem „Engel des Herrn“, dass dieser wahrscheinlich „weder eine unbestimmte Bezeichnung noch ein eigenständiges Engelsindividuum “3 ${ }^{3}$ darstellt, sondern eine Rolle, die von unterschiedlichen Engeln besetzt wird, ohne dass sich diese klar gegeneinander abgrenzen ließen.

So sehr Engel zwischen Ort und Ortlosigkeit, Singular und Plural schwanken, so zwiespältig ist auch ihr Verhältnis zur Zeit. Denn weder kommt Engeln Ewigkeit (aeternitas) zu wie Gott, noch sind sie als unsinnliche Wesen auf die menschliche Zeit (tempus) beschränkt. Als Geschöpfe, die einen Anfang, aber kein Ende haben, weist Thomas von Aquin ihnen das Zeitmaß des aevum zu, einer endlosen Zeit, die im Dazwischen von historischer Zeit und Ewigkeit angesiedelt ist. ${ }^{4}$ Die Engel ver-

1 August Twesten, Vorlesungen über die Dogmatik der Evangelisch-Lutherischen Kirche, nach dem Compendium des Herrn Dr. W. M. L. de Wette, Bd. 2, Hamburg 1837, S. 308.

2 Thomas von Aquin, Summe der Theologie. Die katholische Wahrheit oder die theologische Summa des Thomas von Aquin. Deutsch wiedergegeben durch Ceslaus Maria Schneider, Regensburg 1886-1892, Prima Pars, Quaestio 50, Artikel 3c.

3 Hafner, Angelologie, S. 232.

4 Vgl. die Ausführungen von Thomas von Aquin: „So haben die Himmelskörper immer dasselbe substantiale Sein; jedoch dieses Sein ist verbunden mit dem thatsächlich beständigen Wechsel von Ort zu Ort. Und auch die reinen Geister gehen nicht von einer Substanz in die andere über; aber gemäß ihrer freien Wahl können sie vom Guten zum Bösen abfallen und ebenso den Ort wechseln, auf den die wirkende Kraft ihrer Natur sich richtet. Solche Substan- 
binden so sakrale Ewigkeitszustände und weltliche Geschichte. Ihre räumlich und zeitlich unbestimmte Übermenschlichkeit trägt wesentlich zu der Gefährdung bei, die die Engel für den alleinigen Machtansprach Gottes bedeuten.

Eine weitere Bedrohung liegt in ihrer sinnlichen Präsenz, die mit der Unsichtbarkeit Gottes kontrastiert. Bereits Paulus beziehungsweise sein Umfeld sieht und verurteilt die Gefahr der Idolatrie eines sich verselbständigenden Engelkults, in dem die Engel nicht bloß als mediale Träger, sondern als Adressaten eigener Anbetung wahrgenommen werden:

Lasst euch den Siegespreis von niemandem nehmen, der sich gefällt in Demut und Verehrung der Engel und sich dessen rühmt, was er geschaut hat, und ist ohne Grund aufgeblasen in seinem fleischlichen Sinn und hält sich nicht an das Haupt, von dem her der ganze Leib durch Gelenke und Bänder gestützt und zusammengehalten wird und wächst durch Gottes Wirken.

(Kol 2,18-19)

Auch den potentiellen Machtanspruch der Engel, der aus ihrer exekutiven Tätigkeit herrührt, gilt es zurückzuweisen. So betont Pseudo-Dionysius Areopa-

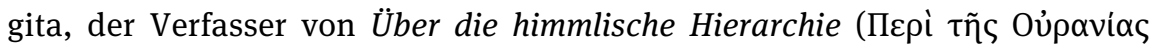

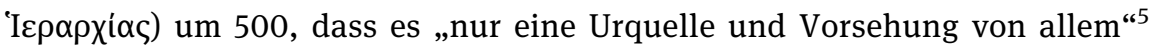
gebe. Daraus folgt: „In keinem Fall darf man der Ansicht sein, daß die Urgottheit nach der Auswahl des Loses die Juden leite, Engel dagegen auf eigene

zen also mißt das ,Ävum' und deshalb steht es in der Mitte zwischen Ewigkeit und Zeit. Das substantiale Sein, welches von der Ewigkeit gemessen wird, ist weder in sich selber veränderlich noch mit Veränderlichkeit im Thätigsein verbunden. Die Zeit ist das Maß für das Veränderliche im substantialen Sein selber und hat deshalb ein Vorher und Nachher. Das ,Ävum‘ aber hat kraft seines Wesens in sich selber kein Vorher und Nachher; aber nebensächlich kann mit Rücksicht auf die Thätigkeit das mit ihm verbunden werden. Die Ewigkeit hat weder in ihrem Sein ein Vorher und Nachher, noch duldet sie es an denselben“ (Thomas von Aquin, Summe der Theologie, Prima Pars, Quaestio 10, Artikel 5a). Vgl. auch die Erläuterung von August Twesten: „Eigentlich soll das aevum oder die aeviternitas ein Mittleres seyn zwischen der aeternitas, welche Gott, und der Zeit, die der Sinnenwelt zukommt [...]; wenn man aber den Unterschied bloß darin setzt, daß die Ewigkeit weder Anfang noch Ende, das aevum zwar einen Anfang aber kein Ende, die Zeit Anfang und Ende habe, so hat man überhaupt nur die Zeit gedacht, und namentlich den Engeln nichts anders beygelegt, als was dem menschlichen Geiste auch zukömmt. Auf etwas Tieferes deutet Scaligers, von Gerhard (Loc. de creatione $\S$. 51) verworfene Unterscheidung von aevum und aetas; nach ihr hat letzteres, welche uns zukömmt, die Zeit, erstere, welche den Engeln, die Ewigkeit, die das Wesen Gottes selbst ist, zum Maße“ (Twesten, Vorlesungen über die Dogmatik der Evangelisch-Lutherischen Kirche, S. 309). Vgl. außerdem Hafner, Angelologie, S. 116-117.

5 Pseudo-Dionysius Areopagita, Himmlische Hierarchie. In: Des heiligen Dionysus Areopagita angebliche Schriften über die beiden Hierarchien. Aus dem Griechischen übersetzt von Josef Stiglmayr, München 1911, hier Kapitel 9, § 4. 
Faust, sei es in gleicher, sei es in entgegengesetzter Tendenz, oder irgend welche andere Götter an der Spitze der andern Völker stehen.“6

Um die Gefahr einer angelischen Machtaneignung zu bannen, ist eine ausgefeilte Taxonomie nötig. Ordnung im Bereich der Angelologie meint nicht Heterarchie, sondern Hierarchie. Immer geht es um Fragen der Rangordnung. Dabei ist die „himmlische Hierarchie [...] das Muster und Modell für die kirchliche“" , wie es bei Thomas von Aquin heißt. Auch im Bereich der Innerlichkeit sind Engel modellbildend: Als Bollwerk gegen lasterhafte Dämonen wird der Engel zum tugendhaften, schützenden Alter Ego. ${ }^{8}$ Angelologien, die derartige Klassifizierungen entworfen haben, sind so vielzählig (und damit in ihrer Pluralität und Verschiedenartigkeit selbst wiederum tendenziell ordnungsbedrohend), dass es im Rahmen dieser Arbeit nicht möglich und auch nicht nötig ist, genauer auf die verschiedenen Ordnungsentwürfe einzugehen. Wichtig ist vielmehr, anhand exemplarischer Punkte das Spannungsfeld von Ordnungskonstitution und Ordnungsbedrohung auszumessen, das in den Angelologien zum Ausdruck kommt. Die Bedrohung ist dabei teils nur ex negativo zu erahnen, als das Moment, das die angelologische Hierarchisierung allererst erforderlich macht. Das Grundmuster der Angelologie besteht in einer Verknüpfung von Hierarchie (es gibt höher- und niederrangige Engel), Axiologie (je allgemeiner, geistiger, substanzloser, desto besser), Topologie (die höheren Engel sind Gott und damit dem geistigen Bereich näher, die niederen haben Berührung mit der stofflichen Welt) und Epistemologie (die höheren Engel wissen mehr).

In Pseudo-Dionysius Areopagitas kanonischer, auf einer neuplatonischen Abbild- und Partizipationstheorie fußender Systematik ist die Engelshierarchie Teil der „durch die göttliche Gesetzgebung festbestimmten Ordnung“ ${ }^{\text {“9 }}$. In ihr werden nach einem konzentrisch gegliederten Stufenprinzip abnehmender Vollkommenheit göttliche Schönheit, Erleuchtung und Offenbarung vermittelt. Es gibt neun Engelchöre, die sich in drei Triaden gliedern und deren Distinktionskriterium die Nähe zum göttlichen Urquell darstellt. Ihre Funktion liegt im Empfangen und Mitteilen von „Reinigung, Erleuchtung und Vollendung“10. Die

6 Pseudo-Dionysius Areopagita, Himmlische Hierarchie, Kapitel 9, § 4.

7 Thomas von Aquin, Summe der Theologie, Prima Pars, Quaestio 108, Artikel 4 a.

8 Origenes spricht davon, dass ,jeder, auch der geringste in der Gemeinde, einen eigenen Engel hat, der nach dem Ausspruch des Heilandes allezeit das Angesicht Gottes, des Vaters sieht, und dieser ohne Zweifel mit seinem Schützling Ein's ist“ (Origenes, Über die Grundlehren der Glaubenswissenschaft. Wiederherstellungsversuch von Dr. Karl Fr. Schnitzer, Stuttgart 1835, S. 158). Zu den Schutzengeln vgl. auch Thomas von Aquin, Summe der Theologie, Prima Pars, Quaestio 113, Artikel 1-8.

9 Pseudo-Dionysius Areopagita, Himmlische Hierarchie, Kapitel 4, § 3.

10 Pseudo-Dionysius Areopagita, Himmlische Hierarchie, Kapitel 7, § 2. 
erste Triade setzt sich aus Seraphim, Cherubim und Thronen zusammen. Darauf folgen in der zweiten Herrschaften, Gewalten und Mächte und in der dritten Fürstentümer, Erzengel und Engel. ${ }^{11}$ Engel im engeren Sinne stellen als unterste Stufe der Hierarchie den Berührungspunkt zur Menschenwelt dar, in die sie die göttliche Erleuchtung tragen. In diesem Kontakt von untersten Engeln und obersten Menschen ist die Analogie von göttlicher und kirchlich-weltlicher Ordnung verankert. Fast 800 Jahre später greift Thomas von Aquin auf das streng hierarchisch aufgebaute Verweis- und Spiegelmodell der Engel zurück und verfeinert es. Als doctor angelicus räumt er der Engellehre in seiner zwischen 1265 bis 1273 entstandenen Summa Theologica breiten Raum ein und geht in den Quaestiones 106-114 ausführlich auf die Bedeutung der Engel (auch der bösen) für die Weltregierung ein. Indem Engel alles Körperliche, also Konkrete und damit Minderwertige, leiten, greifen sie in das Geschehen auf der Erde ein. ${ }^{12}$

Der Zusammenhang von Gutem, Gottesnähe und tugendhaftem Verhalten, in dem alle vernunftbegabten Kreaturen durch den Gebrauch des freien Willens navigieren, wird schon früher bei Origenes in De principiis, wahrscheinlich zwischen 212 und 215 entstanden, deutlich:

\footnotetext{
Und daraus [dass die Urwesentlichkeit des Guten nur der Trinität zukommt, L.Z.] geht denn hervor, daß aller Abfall die natürliche Folge der eigenen Willensrichtung ist; und daß, sowie die höheren Geister nicht nach einem Vorzugsrechte, sondern nach ihrem sittlichen Verdienst ihren Rang behaupten, die vernünftigen Geschöpfe überhaupt nur durch Trägheit und Erschlaffung in irdische Leiber versanken, und, weil sie in ihrem frühern Zustande gesündigt haben, hier gleichsam an einem Strafort sich befinden. ${ }^{13}$
}

Gut und böse besetzen jeweils eigene Sphären, die in spezifischer Weise angeordnet sind und eine Reihe weiterer Oppositionen wie hell und dunkel, leicht und schwer, ätherisch und leiblich oder rein und sündhaft kodieren. Ihre Grundlage ist eine dichotomische Axiologie, in der gut und böse keine menschlichen Bewertungskategorien, sondern kosmisch-angelische Entitäten darstellen, die stufenförmig strukturiert sind. ${ }^{14}$ Entsprechend handelt es sich weniger um ein moralisch diffiziles Bewertungsinstrument als vielmehr, so ließe sich die Fragestellung von gut und böse hier säkularisieren, um die Leitdifferenz in einer räumlichen Ordnung. Allerdings handelt es sich bei dem Bösen, das sich in eine Ordnung einfügt, immer schon um ein domestiziertes Böses. Das wahrhaft Böse negiert diese Leitdifferenz und damit die Ordnung selbst - eine Eigenschaft, die sich bei Engeln in vie-

11 Vgl. Pseudo-Dionysius Areopagita, Himmlische Hierarchie, Kapitel 6, § 2.

12 Vgl. Thomas von Aquin, Summe der Theologie, Prima Pars, Quaestio 110, Artikel 1b.

13 Origenes, Über die Grundlehren der Glaubenswissenschaft, S. 57-58.

14 Vgl. Dürr, Der Engel Mächte, S. 26. 
lerlei Hinsicht findet. So verflüssigen sich bei näherem Hinsehen die Oppositionen schon in den Angelologien, denn sämtliche Eigenschaften von Geschöpfen sind nicht absolut gegeben, sondern immer relational, als Grad der Teilhabe an oder Abkehr von Gott. Da diese Eigenschaften sich in einem dynamischen Austausch herausbilden, bleiben auch alle unter Gott stehenden Gegensätze keine trennscharfen. So heißt es in $\S 1$ der Himmlischen Hierarchie von Pseudo-Dionysius Areopagita: „Gleich allen Gaben Gottes steigt auch der Strahl göttlicher Erleuchtung vom Vater hernieder; er fährt aber auch hinwieder zu der einen Quelle empor und bewirkt Einheit und Ähnlichkeit mit Gott.“15

Diese Vermittlungen, die in Vermischungen übergehen, werfen die Frage auf, wie durchlässig die Grenze zwischen irdischer und himmlischer Sphäre ist. Dabei geht es nicht nur um räumliche, sondern immer auch um zeitliche Kontaktpunkte, nämlich um das Verhältnis von historischer Gegenwart und dem kommenden Gericht und Reich Gottes. In diesem werden die Karten je nach tugend- oder lasterhaftem Verhalten neu gemischt, sodass „aus Engeln Menschen oder Dämonen, und aus diesen wieder Menschen oder Engel werden können“ “16, wie Origenes meint. Der Natur nach können Menschen nicht zu Engeln werden, durch Gnade aber ist dies sehr wohl möglich, was Thomas von Aquin, der in der Summa theologica eine Synopsis antiker Angelologien präsentiert, mit Verweis auf Lk 20,36 einräumt: „Die Kinder der Auferstehung werden im Himmel gleich den Engeln sein. “17 Darüber hinaus kursiert auch der wirkmächtige Gedanke, dass die gegenwärtige Ordnung bereits in der Jetztzeit auf jenes himmlische Reich hin transzendiert werden kann. So nähern sich jungfräuliche beziehungsweise asketisch lebende Menschen, die aus der irdischen Welt heraus- und in die übernatürliche Sphäre hineinragen, einem engelhaften Dasein an. ${ }^{18}$ Pseudo-Dionysius konzediert dieses Privileg immerhin dem Bischof: Er darf in seiner Tätigkeit als Verkünder und Deuter göttlicher Weisheiten als Engel bezeichnet werden. ${ }^{19}$ Die an den Engeln fixierte Durchlässigkeit der scheinbar strikten Hierarchie funktioniert also in beide Richtungen: Engel ermöglichen den Menschen die Teilhabe an der göttlichen Erleuchtung, wie umgekehrt Menschen aufgrund der Fehlbarkeit von Engeln in die himmlische Hierarchie aufsteigen können.

All den ausgefeilten angelologischen Hierarchien zum Trotz wurde jedoch immer wieder das „Chaos“ festgestellt, das unter den Engeln herrscht. ${ }^{20}$ Der

15 Pseudo-Dionysius Areopagita, Himmlische Hierarchie, Kapitel 1, §1.

16 Origenes, Über die Grundlehren der Glaubenswissenschaft, S. 76.

17 Thomas von Aquin, Summe der Theologie, Prima Pars, Quaestio 108, Artikel 8b.

18 Vgl. Kapitel 2.3 dieser Studie.

19 Vgl. Pseudo-Dionysius Areopagita, Himmlische Hierarchie, Kapitel 12, § 2.

20 Vgl. Serres, Die Legende der Engel, S. 82. 
Kunsthistoriker und Künstler Boris von Brauchitsch befindet, dass es „nicht einmal den Menschen mit ihrem ausgeprägten Drang zu Bürokratie und Statistik [...] gelungen [ist], Eindeutiges über Rangordnungen, Anzahl, Aufgabenbereiche und Erscheinungsformen der Engel herauszufinden“21. Das Vertrackte ist allerdings, dass dieses Chaos der Bürokratie selbst erwächst. Die Angelologie ist als Entstehungsort moderner Verwaltungsbegriffe wie „Ämter“ und „Ministerien“22 die heimliche Wiege der Bürokratie. Und das Sprechen über Engel bewegt sich immer schon im Bereich des Bürokratischen. Das wird an den begrifflichen Kongruenzen von himmlischen und weltlichen Hierarchien (Herrschaften, Obrigkeiten, Mächte oder Throne) sowie der Konstruktion von kirchlichen und weltlichen Ämtern als Imitation der Engelsordnung deutlich. ${ }^{23}$

Die Verwandtschaft von Angelologie und Bürokratie nimmt Giorgio Agamben zum Ausgangspunkt, um die Engel als Archetypen hierarchischer Ordnung und Regierungsmacht zu entwerfen. Die argumentative Grundlage bildet das Dispositiv der trinitarischen oikonomia (oikovo $\mu$ í $\alpha$ ), die nach Agamben das Verwaltungs- und Regierungsparadigma des Christentums darstellt. Demnach sind die Engel konstitutive Träger der oikonomia, weil sie die Spannung des dreifaltigen Gottes mit der Idee seiner Einheit vermittelten. Der Preis für diese Einheit der göttlichen Substanz besteht nach Agamben in der Vielfalt von Figuren und Praktiken und dem Bruch von Wesen und Ökonomie, von Herrschaft und Regierung Gottes, wodurch sich ein gnostisches Element ins Christentum eingeschlichen habe. ${ }^{24}$ Mit der für das Abendland zentralen Kategorie des Willens sollte dann zwischen den Ebenen einer absoluten und einer geordneten Macht vermittelt und so eine verbindungslose gnostische Teilung in Schöpfergott und Weltenlenker einerseits und eine heidnische Identität von Sein und Tat andererseits verhindert werden. ${ }^{25}$ Vor diesem Hintergrund behauptet Agamben, „daß die christliche Theologie von Anfang an nicht im Zeichen der Politik und des Staates steht, sondern in dem der Betriebswirtschaft““26. In Form einer „Regierungsmaschine“ komme ihr die Aufgabe zu, die Teilung des Seins in einen transzendenten und einen immanenten Bereich zu koordinieren. Diese „Regierungsmaschine“ funk-

21 Boris von Brauchitsch, Jenseits von Eden. Engel in der zeitgenössischen Kunst. In: Die Wiederkunft der Engel. Beiträge zur Kunst und Kultur der Moderne, hg. von Markwart Herzog, Stuttgart 2000, S. 101-120, hier S. 101.

22 Agamben, Vorwort, S. 12-13.

23 Dabei wurde die entsprechende Terminologie von Verwaltung und Regierung zuerst im Bereich der Angelologie ausgearbeitet, wie Agamben betont (vgl. Agamben, Herrschaft und Herrlichkeit, S. 189).

24 Vgl. Agamben, Herrschaft und Herrlichkeit, S. 72.

25 Vgl. Agamben, Herrschaft und Herrlichkeit, S. 72.

26 Agamben, Herrschaft und Herrlichkeit, S. 87. 
tioniere damit „gleichsam als unablässige Theodizee, in der die Herrschaft der Vorsehung die Regierung des Schicksals legitimiert und begründet und diese Ordnung, die erstere festgesetzt hat, garantiert und verwirklicht““27. Die Funktionstüchtigkeit der Regierungsmaschine ist wesentlich an die Vermittlung der Herrlichkeit beziehungsweise der Verherrlichung in Form der liturgischen Doxologie gebunden, da nur so eine Versöhnung der Brüche möglich ist. ${ }^{28}$

In dieser Regierungsmaschine nehmen die Engel mit ihrer verwaltenden und lobpreisenden Tätigkeit eine zentrale Rolle ein. ${ }^{29}$ Darin liegt für Agamben die Idiosynkrasie der christlichen Angelologien. Zur Erhaltung des Trinitätsparadigmas habe man danach getrachtet, die durch die administrative, heilsvermittelnde Tätigkeit begründete Engelsartigkeit Christi zu beseitigen und die Angelologie „vollständig in eine bürokratisch-exekutive Struktur der göttlichen Vorsehung zu überführen“30. Diese Vergöttlichung des angelischen Regierungsparadigmas wiederum habe wesentlich zur Vormachtstellung des christlichen Abendlandes beigetragen:

Wenn die Weltregierung noch immer (auch wenn wir heute nicht absehen können, wie lange noch) in den Händen des christlichen Abendlandes liegt, hängt dies fraglos auch mit dem Umstand zusammen, daß das Christentum als einzige der drei monotheistischen Religionen die Regierung der Welt in die Gottheit eingefügt und derart die englische [sic] Macht vergöttlicht hat. ${ }^{31}$

Bei Agamben völlig ausgespart bleibt allerdings die Unordnung, ja Chaos stiftende Wirkung der Engel. Diese hängt mit der Ambivalenz der Engelshierarchien selbst zusammen, weil sie die in ihnen angestrebte Einhegung angelozentrischautonomer Tendenzen zugleich unterminieren. Denn die Angelologien schaffen nicht nur keine endgültige (Unter-)Ordnung der Engel, was vor allem hieße, ihre latente Schöpferanmaßung in die Schranken zu weisen; sie sorgen vielmehr dafür, dass ihr Machtbereich als Teil der himmlischen Regierung ausgeweitet wird. ${ }^{32}$ Damit entsteht aufs Neue die Notwendigkeit, die Machtfülle der Engel zu beschneiden. Deutlich sieht man das bei Thomas von Aquin, der ausführlich erläutert, wieso Körper, obwohl sie von Engeln gelenkt werden, diesen nicht unmittelbar folgen, ${ }^{33}$ und warum Engel selbst keine Wunder vollbringen können. ${ }^{34}$

27 Agamben, Herrschaft und Herrlichkeit, S. 157.

28 Vgl. Agamben, Herrschaft und Herrlichkeit, S. 276.

29 Vgl. Agamben, Vorwort, S. 12.

30 Agamben, Vorwort, S. 21.

31 Agamben, Vorwort, S. 24.

32 Vgl. Dürr, Der Engel Mächte, S. 19.

33 Vgl. Thomas von Aquin, Summe der Theologie, Prima Pars, Quaestio 110, Artikel 2.

34 Vgl. Thomas von Aquin, Summe der Theologie, Prima Pars, Quaestio 110, Artikel 4. 
Solche kleinteiligen Begründungen wurden in vielen Angelologien unternommen. Während Thomas von Aquin sich an den hierarchischen und exekutiven Aspekten abarbeitet, liegt der Fokus bei Pseudo-Dionysius vor allem auf den Paradoxien der Engelsdarstellungen. Der Informationsmangel und die Widersprüchlichkeiten, die das Auftreten von Engeln in der Bibel begleiten, werden durch exzessive Begründungen in den Angelologien überkompensiert. Als Scharnier zwischen geistiger und stofflicher Welt verhandeln Engel die zentralen Fragen von Ordnung, Macht und Regierung. Dabei wurden mit Origenes und Pseudo-Dionysius wichtige Baumeister der Angelologie später selbst als ketzerisch oder wenigstens unchristlich geächtet. ${ }^{35}$

Der entgegengesetzte Weg, um mit den Unstimmigkeiten der Engel fertigzuwerden, wird dann mit der Reformation beschritten, in der die konsequente Konzentration auf die Schrift großangelegte angelologische Spekulationen unterbindet. Hier gibt es keinerlei weiterführende Überlegungen zu Sein und Tätigkeit der Engel. Vielmehr werden sie zu einem formalen Restbestand ohne soteriologisch-ekklesiologische Funktion für das christliche Dogma marginalisiert, allerdings ohne dass ihre Existenz grundlegend bezweifelt worden wäre diese wird erst in der Aufklärung zu einem Stein des Anstoßes. ${ }^{36}$ Spätestens in dieser Zeit kippt die von Agamben postulierte Hierarchie- und Herrschaftsaffinität der Engel dann in ihr Gegenteil und sie werden vor allem als Bedrohung einer binären Ordnung wahrgenommen.

Im 18. Jahrhundert lehnt Immanuel Kant etwa Engel nicht nur als unbeweisbare Realität, sondern vor allem als Prinzip ab. ${ }^{37}$ Auch Gott kann nach Kant als transzendentaler Grund der Welt nicht sinnvollerweise Gegenstand einer Existenzaussage sein. ${ }^{38}$ Allerdings steht er für die „systematische Einheit, Ordnung und Zweckmäßigkeit der Welteinrichtung“39, die zum notwendigen regulativen Prinzip der Naturerforschung erhoben wird. Aus diesem Grund kann Kant „in dieser Idee gewisse Anthropomorphismen, die dem gedachten regulativen Prinzip beförderlich sind, ungescheut und ungetadelt erlauben “40. Gott fungiert als transzendentaler Stabilitätsanker eines systematischen Ordnungs- und Zweckmäßigkeitsgedankens im Hinblick auf die Naturerkenntnis

35 Vgl. Hafner, Angelologie, S. 157.

$36 \mathrm{Zu}$ dieser Entwicklung vgl. Dürr, Der Engel Mächte, S. 73-89.

37 Vgl. Kurt Röttgers, Die Physiologie der Engel. In: Engel in der Literatur-, Philosophie- und Kulturgeschichte, hg. von Monika Schmitz-Emans u. Kurt Röttgers, Essen 2004, S. 29-51, hier S. 39.

38 Vgl. Immanuel Kant, Kritik der reinen Vernunft, Hamburg 1998, S. 750-751.

39 Kant, Kritik der reinen Vernunft, S. 751.

40 Kant, Kritik der reinen Vernunft, S. 751. 
sowie als Stützpfeiler der Moralphilosophie. ${ }^{41}$ Das ist deshalb so wichtig, weil der apriorische Anspruch der Moralphilosopie, die den unter moralischen Gesetzen stehenden Menschen als Endzweck der Schöpfung setzt, aus der Natur nicht hergeleitet werden kann. Engel, die sich grundsätzlich zwiespältig zum Gedanken der Ordnung verhalten, kann Kant anders als Gott nicht als Anthropomorphismus tolieren - denn sie fügen sich nicht naht- und reibungslos in sein System mit universalem Anspruch ein. Diese Aversion reicht so weit, dass Kant es weitgehend vermeidet, Engel beim Namen zu nennen. ${ }^{42}$

Das kantische Erkenntnisgebäude funktioniert über konzise Grenzziehungen der Vernunft, die der Engel als Grenzfigur auch als bloß analogische Metapher gefährdet. Nach Kant ist eine anthropomorphistische Vorstellung übersinnlicher und gewissermaßen frei flottierender Wesen ein Kennzeichen der Dämonologie, sodass er „sich der Engel praktisch dadurch entledigen [kann], dass er sie auf eine empirische Stufe mit den aus menschlicher Furcht geborenen Göttern stell[t $\mathrm{t}]^{\text {“43. Anders }}$ als Gott, den man als übergeordnete Ursache sinnvoll annehmen kann, damit die Menschen in ihrem Bemühen um moralisches Handeln nicht demotiviert werden, ${ }^{44}$ kommt den Engeln keine derartige Stabilisierungsfunktion zu. Entsprechend werden sie zu einer Gefahr für den kantischen Monotheismus, da für sie als transreale, unsinnliche Geschöpfe keine valide Urteilsbasis besteht. Ohne diese aber verweigern sie sich einer klaren Einordnung und werden so zum potentiellen Affront für das Primat der Vernunft beziehungsweise für den strikt trennenden Verstand und das Sittengesetz. Als ein unkontrollierbarer Überschuss führen sie ab vom geraden Weg der sittlichen Vernunft, sodass ihnen nicht einmal mehr die ethische Funktion zukommt, das Gute zu illustrieren.

41 In der Kritik der Urteilskraft (1790) hält Kant an der theoretischen Unerkennbarkeit Gottes fest - seine Existenz kann nur als regulatives Prinzip nach den Begriffen der praktischen Vernunft für die subjektiv-reflektierende, nicht aber für die objektiv-bestimmende Urteilskraft angenommen werden (vgl. Immanuel Kant, Kritik der Urteilskraft. Schriften zur Ästhetik und Naturphilosophie. Werke III, hg. von Manfred Frank u. Véronique Zanetti, Frankfurt am Main 1996, S. 479-880, hier S. 843). Die Idee einer obersten transzendentalen Kausalität wird in der Ethikotheologie gesetzt, die der Annahme der einen letzten Weltursache, auf die die Naturzwecke hin organisiert sind und die eine rein naturimmanent verfahrende Beweisführung überschreitet, als einem Postulat der menschlichen Vernunft Rechnung trägt. Dieses allwissende, allmächtige, allgütige, allpräsente, gerechte und ewige Wesen bestimmt nicht nur die Gesetze der Natur, sondern wirkt nach Kant auch als das ,gesetzgebende Oberhaupt in einem moralischen Reiche der Zwecke“ (Kant, Kritik der Urteilskraft, S. 826).

42 Vgl. Röttgers, Die Physiologie der Engel, S. 38-39.

43 Dürr, Der Engel Mächte, S. 87. Vgl. dazu Kant, Kritik der Urteilskraft, S. 829.

44 Vgl. Kant, Kritik der Urteilskraft, S. 829. 
Zygmunt Bauman verortet das scheinbar voraussetzungslose, formalistische System Kants in einem konkreten machtpolitischen Kontext und verweist auf die untrennbare Verquickung der Vision von geistiger und praktischer Herrschaft. Die Aufgabe der kantischen Ordnung sieht er darin,

die Grenze der „organischen Struktur“ scharf und deutlich zu markieren, was bedeutet, das „Mittlere auszuschließen“, alles Zweideutige, alles, was quer über der Barrikade sitzt und auf diese Weise den vitalen Unterschied zwischen innen und außen kompromittiert, zu unterdrücken oder auszurotten. ${ }^{45}$

Die Aversion Kants gegen Engel lässt sich ebenso wenig begreifen wie die Engelbegeisterung der Gegenwart, wenn man Engel auf ihre herrschaftsaffine Dimension reduziert. Agambens Beobachtung, dass „die Angelologie unmittelbar mit einer Theorie der Macht zusammenfällt“ und „der Engel die Verkörperung der Weltregierung schlechthin ist“" ${ }^{\star 46}$, berührt wesentliche Aspekte der Angelologie. Allerdings bleibt unbeachtet, dass deren straffe Hierarchisierung nicht nur als Reaktion auf den „angelologische[n] Ursprung der Christologie“ ${ }^{47} \mathrm{zu}$ verstehen ist, der das Trinitätsparadigma bedroht. Die Gründe für die Identifikation der Engel mit dem Herrschaftsparadigma liegen ebenso sehr in den Leerstellen, Unstimmigkeiten und Provokationen, die mit dem Auftreten von Engeln in der Bibel verbunden sind und ihre Einhegung so dringlich machten. Indem die Botenrolle betont und der Engel liturgisch fixiert wurde, sollte der Vorstellung von Wesen mit eigener Machtsphäre, wie sie Mittlerfiguren in anderen Glaubensvorstellungen zukam, entgegengewirkt werden. In den hier betrachteten Angelologien verfügen die Engel über keinen eigenen Raum, sondern besetzen die Schwelle von intelligibler und materieller Welt. Sie verlieren damit vollends ihre Potenz als eigenständige Zwischenwesen, wie sie in der Antike und im nichtisraelitischen Raum bekannt waren. ${ }^{48}$ Erst wenn man die Gründe mitbedenkt, die die Depotenzierung der Engel allererst nötig gemacht haben, gerät auch die Dialektik von Regierung und Regierungssturz in den Blick, die die Figur des Engels für die moderne Literatur so attraktiv werden ließ.

Alle hier skizzierten Phänomene betreffen Ordnungsaspekte. Zur Entstehungszeit der betrachteten Angelologien wurde die göttliche Ordnung selbst nicht hinterfragt. Wohl aber wird die Frage der Ordnung auf einer religiösen

45 Zygmunt Bauman, Moderne und Ambivalenz. Das Ende der Eindeutigkeit, Hamburg 2005, S. 48.

46 Giorgio Agamben, Die Beamten des Himmels, Frankfurt am Main; Leipzig 2007, S. 69.

47 Agamben, Die Beamten des Himmels, S. 21.

48 Vgl. Dürr, Der Engel Mächte, S. 32. 
Binnenebene relevant und zwar immer dort, wo Engel involviert sind. ${ }^{49}$ Das betrifft die Hierarchie von himmlischer und irdischer Ordnung in der christlichen Theologie im Allgemeinen wie auch das konkrete Wesen und Wirken, das Engeln in ihr zugeschrieben wird. Diese Ordnungsaspekte des Engels bieten Anschlüsse für Ordnungsfragen, die Rilke, Benjamin, Mann und Aichinger beschäftigt haben. Der Ausgangspunkt ist dann nicht die gesetzte göttliche Ordnung, sondern im Gegenteil eine bedrohte, teils kriegszerstörte Ordnung. Als Figur zwischen Ordnungssturz und Ordnungskonstitution wird über den Engel die Verheerung der Welt und gleichzeitig die Möglichkeit einer neuen Ordnung reflektiert. In dieser Funktion ist er wesentlich mit politischen Projekten und Gestaltungsutopien verbunden. Das betrifft sowohl Fragen nach einer neuen Ordnung auf politisch-struktureller Ebene als auch eine Verwandlung des Menschen durch angelisierende Praktiken. Eine Spielart der Ordnungsfrage ist die Spannung von Reinheit und Hybridität.

\subsection{Reinheit und Hybridität in Genese und Wesen der Engel}

Engel, so eine wichtige Beobachtung, stehen sowohl systematisch als auch genealogisch in einem Spannungsfeld von Reinheit und Hybridität. Nach Thomas von Aquin ist der Engel „eine für sich bestehende Form ohne Stoff“50, Pseudo-Diony-

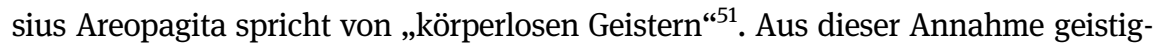
stoffloser Wesen, die von den Verstrickungen des „sündigen Fleisches“ (Röm 8,3) nicht tangiert sind, ergibt sich das ihnen zugeschriebene Attribut der Reinheit. Pseudo-Dionysius Areopagita expliziert dies für die oberste Engel-Triade folgendermaßen: „Für rein muß man diese Geister erachten, nicht nur insofern, als ob sie von unheiligen Flecken und Makeln befreit und materiell-sinnlichen Phantasievorstellungen unzugänglich wären, sondern in dem Sinne, daß sie ungetrübt über jede Schwächung und über alles minder Heilige hinaus entrückt sind. “52

In Abgrenzung zum Menschen werden Engel auch ganz konkret als von dem Kreislauf körperlicher Einverleibungen und Ausscheidungen losgelöste Wesen

49 So verweist Agamben auf die Kontinuität zwischen der providentiellen Weltregierung und dem wissenschaftlichen Weltbild der Moderne, die beide auf einem Wechselspiel von allgemeinen Gesetzen und kontingenten zweiten Ursachen immanenter Wirkungen beruhten (vgl. Agamben, Herrschaft und Herrlichkeit, S. 149-150).

50 Thomas von Aquin, Summe der Theologie, Prima Pars, Quaestio 50, Artikel 5b.

51 Pseudo-Dionysius Areopagita, Himmlische Hierarchie, Kapitel 2, § 4. Hingegen wird in Teilen der patristischen Tradition ein „ätherischer Leib“ angenommen. Zur Diskussion bezüglich des Engelleibs vgl. Dürr, Der Engel Mächte, S. 164-166.

52 Pseudo-Dionysius Areopagita, Himmlische Hierarchie, Kapitel 7, § 2. 
gedacht, deren Essenz diaphaner Geist ist. Damit sind die Assoziationen von Schwerelosigkeit, Entrückung und besonderer Gottesnähe verknüpft. PseudoDionysius zufolge haben Engel als reine Geistwesen höheren Anteil an der göttlichen Schönheit und „,bilden sich in rein geistiger Weise zu Nachbildern Gottes um“53. Als „Spiege[1]“54 vermitteln sie zwischen Gott und Menschen, indem „die urgöttliche Erleuchtung in sie zuerst einstrahlt und dann durch sie die unsere Erkenntnis überragenden Offenbarungen uns vermittelt werden “55. Trotz seiner Geistigkeit ist dem Engel die Fähigkeit gegeben, sich beziehungsweise die unsinnliche Offenbarung Gottes zu materialisieren, um für die menschliche Wahrnehmung erfahrbar zu werden. ${ }^{56}$ Während Pseudo-Dionysius darin vor allem Metaphern sieht, auf die die Verfasser der Bibel zurückgreifen, handelt es sich bei den dort beschriebenen Engelserscheinungen Thomas von Aquin zufolge um tatsächliche Körper, die außerhalb der Einbildungskraft existieren, da sie in der jeweiligen Situation von allen gesehen werden. ${ }^{57}$

Wichtig für die Aufrechterhaltung der angelischen Reinheit ist Thomas allerdings, dass diese Körper nicht wie Körper funktionieren und Engel weder essen noch sexuell aktiv sind. Wenn Engel in der Bibel als essend beschrieben werden wie Raffael im Buch Tobit, dann sei dies „bloß eine äußere Form des Essens, ein Bild, eine Figur davon “58. Interessanterweise thematisiert Raffael selbst diese Spaltung und reflektiert damit die Scheinhaftigkeit des eigenen Scheins: „Während der ganzen Zeit, in der ihr mich gesehen habt, habe ich nichts gegessen und getrunken: ihr habt nur eine Erscheinung gesehen!“ (Tob 12,19) ${ }^{59}$

Somit ist der Engel in mehrfacher Hinsicht scheinhaft: erstens - nach Pseudo-Dionysius' „Lichtmetaphysik“60 - als ästhetischer Reflektor der göttlichen Offenbarung in wandelnden Darstellungen, zweitens - nach Thomas von Aquins „Seinsmetaphysik“61 - mit momenthaft angenommenen Körpern in Bezug auf menschliche Lebensäußerungen, die ausschließlich figurativ zu ver-

53 Pseudo-Dionysius Areopagita, Himmlische Hierarchie, Kapitel 4, § 2.

54 Pseudo-Dionysius Areopagita, Himmlische Hierarchie, Kapitel 3, § 2.

55 Pseudo-Dionysius Areopagita, Himmlische Hierarchie, Kapitel 4, § 2.

56 Vgl. Thomas von Aquin, Summe der Theologie, Prima Pars, Quaestio 51, Artikel 2.

57 Vgl. Thomas von Aquin, Summe der Theologie, Prima Pars, Quaestio 51, Artikel 2b.

58 Thomas von Aquin, Summe der Theologie, Prima Pars, Quaestio 51, Artikel 3c. Kurt Röttgers bezeichnet die Engel daher als „Körper-Simulanten“ (Röttgers, Die Physiologie der Engel, S. 34).

$59 \mathrm{Zu}$ dieser Stelle vgl. auch Hafner, Angelologie, S. 148-149.

60 Engel. In: Religion in Geschichte und Gegenwart. Handwörterbuch für Theologie und Religionswissenschaft, hg. von Hans Dieter Betz, Don S. Browning, Bernd Janowski u. Eberhard Jüngel, Tübingen 1999, S. 1270-1290, hier S. 1281.

61 Engel, S. 1281. 
stehen sind, und drittens, ebenfalls nach Thomas, in ihrer Wirkweise auf die menschliche Vernunft, die sie durch die Einwirkung auf die Einbildungskraft erleuchten. ${ }^{62}$ Der Engel oszilliert also zwischen Reflexionen des Geistig-Numinosen (das sich wiederum in sinnliche Attribute wie äußere Schönheit übersetzt), Figurationen des Sinnlich-Menschlichen und mittelbaren Produktionen der menschlichen Phantasie. Als Vor-Schein ist dieses Changieren zwischen Materialität und Spiritualität im Christentum temporalisiert beziehungsweise futurisiert in der zentralen Botschaft des Christentums, dass das Wort Fleisch werde. ${ }^{63}$ So heißt es in der Summa Theologica: „Daß sie [die Engel, L.Z.] im Alten Testamente Körper annahmen, geschah, damit dies eine Figur und ein Zeichen sei für die heilige Menschwerdung des göttlichen Wortes. “64 Insbesondere dieses Potential des Engels, als eine ästhetische Metalepse Zukünftiges und damit notwendig Unsichtbares in der Gegenwart sichtbar zu machen, wird in Texten der Moderne für Zukunftsentwürfe verschiedenster Art genutzt.

Zugleich sind es die angelischen Vermittlungsakte, die die dem Engel zugeschriebene Reinheit fortwährend unterminieren. Damit sind ordnungspolitische Implikationen verbunden. Nimmt man mit Mary Douglas an, dass „,[n]ur dadurch, daß man den Unterschied zwischen Innen und Außen, Oben und Unten, Männlich und Weiblich, Dafür und Dagegen scharf pointiert, ein Anschein von Ordnung geschaffen werden [kann]“65, wird deutlich, dass der Engel Ordnungen auf mannigfaltige Weise bedroht. Als Wächter steht er zwischen eso- und exoterischem Bereich, als temporale Schwellenfigur zwischen himmlischer und historischer Zeit, als Mittler zwischen überirdischer und irdischer Sphäre, als körperloses beziehungsweise androgynes Wesen über den Geschlechtern und als willensfreies und somit zur Sünde fähiges Geschöpf zwischen göttlichem und widergöttlichem Handeln. Der Engel ist so einerseits Repräsentant und Exekutant der göttlichen Ordnung, andererseits verkörpert er als ambivalente Figur, die sämtliche ordnungskonstitutiven Antagonismen unterläuft, die grundsätzliche Gefahr

62 Vgl. Thomas von Aquin, Summe der Theologie, Prima Pars, Quaestio 111, Artikel 1.

63 Vgl. dazu Ioana Cosma: „However, there is another, positive or plenary aspect of representation and it is connected to the equally theological notions of creation and, very importantly for the present study, revelation. Stating that the world is representation also implies a positive act of realization, of mise en image, an accomplished germination, much like spirit becoming flesh: logos. And this is where angels achieve a crucial function: they are the first expression of this representation of the world. The angels are the primordial bearers of the theophanic vision. They are at once its first accomplishment and perennial expression and passage“ (Cosma, Angels In-Between, S. 33).

64 Thomas von Aquin, Summe der Theologie, Prima Pars, Quaestio 51, Artikel 2c.

65 Mary Douglas, Reinheit und Gefährdung. Eine Studie zu Vorstellungen von Verunreinigung und Tabu, Frankfurt am Main 1988, S. 15-16. 
des Ordnungsbruchs. Da das Wesen der Engel durch Dynamik und Relationalität charakterisiert ist, die ihr instabiles Erscheinungsbild ebenso wie ihre Vermittlungstätigkeit betreffen, lassen sie sich nicht durch statische Kategorisierungen bannen, unterlaufen die distinkten Trennungen und erscheinen in ihrer Bewegung zwischen heterogenen Bereichen als Katalysatoren von bedrohlich empfundener Vermischung. ${ }^{66}$ Der von Mary Douglas postulierte Zusammenhang zwischen Reinheit und Ordnung ist für den Engel deshalb so interessant, weil er einerseits als Statthalter der göttlichen Ordnung firmiert und in der Hierarchie, die PseudoDionysius entwickelt, als besonders geistige - reine - Figur einen hohen Rang einnimmt. ${ }^{67}$ Andererseits scheren Engel mit ihren hybriden Erscheinungsformen, aber auch mit ihrer Vermittlung zwischen heterogenen Bereichen fortwährend aus dieser aufsteigend organisierten Reinheitshierarchie aus. Aufschlussreich ist daher, welche Aussagen anhand der Konzeptualisierung der Engelsfigur, deren Körperlichkeit keine fest gegebene, sondern eine momenthaft erscheinende ist, über die kulturelle Ordnung einer Gesellschaft getroffen werden können.

Die Unreinheit des Engels, in dem sich Gegenwart und Zukunft, Materialität und Spiritualität vermischen, setzt allerdings schon viel früher an, mit den unstimmigen Denotaten, die sich hinter dem Begriff ,Engel` verbergen. Denn die Tendenz zur Vermischung eignet den Engeln nicht nur als Vermittlungsfiguren zwischen göttlicher und weltlicher Hemisphäre innerhalb des biblisch-apokryphen Vorstellungskosmos, sondern betrifft auch ihre konkrete historische Genese. Die Engelsfigur ist nämlich zeitlich wie kulturell mehrschichtig und hybrid, eine Synthese aus älteren Sagen, polytheistischen Glaubenssätzen und sich formierendem israelitischem Monotheismus. ${ }^{68}$ Das liegt nicht nur am kompilatorischen Charakter der Bibel, der notwendigerweise heterogene Schilderungen nach sich zieht. Neben den

66 Vgl. dazu Pseudo-Dionysius Areopagita: „Das Wesen der Gottheit duldet keine Vermischung mit etwas Fremdartigem, wirkt aber doch in den Geschöpfen Reinigung, Erleuchtung und Vollendung“ (Pseudo-Dionysius Areopagita, Himmlische Hierarchie, S. 19).

67 Die besondere Bedeutung von Reinheit und Hybridität beziehungsweise Verunreinigung für Konstitution und Aufrechterhaltung von Ordnungen hat die Sozialanthropologin Mary Douglas mit einem strukturalistisch-kontextualisierenden Ansatz in Reinheit und Gefährdung gezeigt. Schmutz und Verunreinigungen erklärt sie nicht individualpsychologisch, sondern betrachtet sie als kulturübergreifende integrale Konstanten der symbolischen Ordnung einer Gemeinschaft, die sich über das Muster von Schmutz und Schmutzbeseitigung beziehungsweise Ordnungsübertretung und Sanktion konstituiere (vgl. Douglas, Reinheit und Gefährdung, S. 51-52). In den von Reinigungs- und Ordnungsbewegungen geprägten ritualisierten Praktiken werde der Körper zu einem Symbol für die Konstitution und Transgression systemischer Grenzen (vgl. Douglas, Reinheit und Gefährdung, S. 152).

68 Vgl. Hermann Gunkel, Göttinger Handkommentar zum Alten Testament. Genesis, Göttingen 1922, S. 56. 


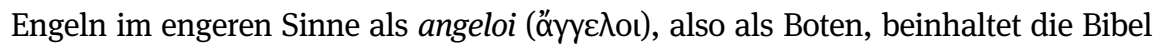
eine Vielzahl weiterer Geistwesen, die vor- und außerisraelitischen Ursprungs sind und erst in nachbiblischen Zeiten unter dem Begriff ,Engel' subsumiert wurden. ${ }^{69}$ Dazu gehören Seraphim (vgl. Jes 6,2), Cherubim (vgl. Ez 1), Throne (vgl. Kol 1,16) sowie Herrschaften, Mächte, Gewalten, Fürstentümer (vgl. Eph 1,21). ${ }^{70}$ Darüber hinaus nahmen aber auch unbestimmte übermenschliche Erscheinungen im Laufe ihrer Rezeptionsgeschichte angelische Konturen an. So etwa bei Jakobs berühmtem Kampf mit dem Engel am Fluss Jabbok, der unter anderem von Chagall, Rembrandt, Delacroix und Dix bildgewaltig, aber ohne biblische Grundlage in Szene gesetzt wurde. Denn in der entsprechenden Bibelstelle ist nur von einem „Mann“ die Rede, der den seinen Bruder Esau fürchtenden Jakob am Jabbok stellt und bis zum Morgengrauen mit ihm ringt. Der Angreifer schlägt Jakob auf die Hüfte, ohne dadurch irgendeinen Vorteil erlangen zu können, und fordert schließlich, als der Morgen naht, Jakob solle von ihm ablassen. Das will dieser aber nicht ohne einen Segen tun. Daraufhin segnet ihn der Mann und gibt ihm den Namen Israel, ohne im Gegenzug seinen eigenen zu verraten (vgl. Gen 32,24-31). Das Verhalten dieses geheimnisvollen Mannes ist einzigartig im Alten Testament und lässt sich mit keinem der gängigen Engelsattribute in Einklang bringen. Aus diesem Grund wurde in der religionswissenschaftlichen Forschung als Vorlage ein (Fluss-)Dämon/Gott ${ }^{71}$ vermutet, jedenfalls eine Figur aus einem präisraelitischen Glauben. ${ }^{72}$

Eine Folge dieser Vermischungen ist, dass es neben den funktional gedachten Boten auch gänzlich andere Engel gibt, die Teil eines himmlischen Hofstaats sind, der auf pagane Götterversammlungen zurückgeht. Aus externen Quellen speisen sich neben den konsultatorisch tätigen Heerscharen auch die Lob singenden beziehungsweise als Gottes Thron fungierenden Seraphim und Cherubim. ${ }^{73}$ Diese höhe-

69 Vgl. Dürr, Der Engel Mächte, S. 30-31. Zu den engelsartigen Wesen in der Antike vgl. Hartmut G. Döhl, Engel und andere Geistwesen in der Antike. Ein Beitrag zu den religionsgeschichtlichen Ursprüngen des Engels. In: Die Wiederkunft der Engel. Beiträge zur Kunst und Kultur der Moderne, hg. von Markwart Herzog, Stuttgart 2000, S. 21-34.

70 Für eine komprimierte Aufzählung vgl. Hafner, Angelologie, S. 127. Für einen Überblick über die Engelsstellen im Alten und Neuen Testament vgl. Monika Schmitz-Emans, Engel. Ein Steckbrief. In: Engel in der Literatur-, Philosophie- und Kulturgeschichte, hg. von Monika Schmitz-Emans u. Kurt Röttgers, Essen 2004, S. 10-28, hier S. 12-13.

71 Vgl. Gunkel, Göttinger Handkommentar zum Alten Testament, S. 364. Im Buch Hosea wird hingegen der Engel aufgerufen und mit Gott verbunden. Dort heißt es: „Darum rechtet der HERR mit Juda; er wird Jakob heimsuchen nach seinem Wandel und ihm vergelten nach seinem Tun. Schon im Mutterleib hat er seinen Bruder gepackt und im Mannesalter mit Gott gekämpft. Er kämpfte mit dem Engel und siegte, er weinte und flehte ihn an“ (Hos 12,3-5).

72 Vgl. Gunkel, Göttinger Handkommentar zum Alten Testament, S. 364.

73 Vgl. Hafner, Angelologie, 230. 
ren Engel sind hybride Figuren par excellence. So werden für die altorientalisch geprägten sechsflügeligen Seraphim als mögliche Vorbilder so unterschiedliche Wesen ins Spiel gebracht wie die Uräus-Schlange aus Ägypten, die babylonische Sphinx oder akkadische janusköpfige Gottheiten. ${ }^{74}$ In puncto Hybridität werden sie nur noch von den polymorphen Cherubim übertroffen, die im Buch Ezechiel folgendermaßen beschrieben werden:

Und ich sah, und siehe, vier Räder standen bei den Cherubim, bei jedem Cherub ein Rad,
und die Räder sahen aus wie ein Türkis, und alle vier sahen eins wie das andere aus; es
war, als wäre ein Rad im andern. Wenn sie gehen sollten, so konnten sie nach allen ihren
vier Seiten gehen; sie brauchten sich im Gehen nicht umzuwenden; sondern wohin das
erste ging, da gingen die andern nach, ohne sich im Gehen umzuwenden. Und ihr ganzer
Leib, Rücken, Hände und Flügel und die Räder waren voller Augen um und um, an allen
vier Rädern. Und die Räder wurden vor meinen Ohren „das Räderwerk“ genannt. Ein
jeder hatte vier Angesichter; das erste Angesicht war das eines Cherubs, das zweite das
eines Menschen, das dritte das eines Löwen, das vierte das eines Adlers. (Ez 10,9-14)

Bei diesem Hybrid aus Fahrzeug, Tier und Mensch ist so viel Vermischung und hyperbolische Ästhetik am Werk, dass seine Beschreibung tendenziell die Vorstellungskraft sprengt und in Unanschaulichkeit umschlägt. In diesem Sammelsurium ist viel zu finden, aber keine Vergeistigung. Sowohl in ihrer menschlich-tierischen Mischgestalt als auch in ihrer Funktion als Wächter (ein Cherub sichert nach der Vertreibung von Adam und Eva den Zugang zum Paradies, vgl. 1 Mos 3,24) weisen die Cherubim starke Ähnlichkeiten zur ägyptischen und mesopotamischen Vorstellungswelt auf. ${ }^{75}$ Neben der kanaanäischen Umgebung übte diese bis zur Zerstörung Jerusalems durch Nebukadnezar 587 v. Chr. nachhaltigen Einfluss auf die israelitische Bildersprache aus. Die überbordende Ästhetik der Engel, die ihrer erklärten Spiritualität zuwiderläuft, bringt die Verfasser von Angelologien in eine Bredouille. So sieht sich Pseudo-Dionysius zu ausführlichen Erklärungen genötigt, „damit wir nicht auch gleich der (ungebildeten) Menge die unheilige Auffassung teilen, als wären die himmlischen und gottähnlichen Geister Wesen mit vielen Füßen und vielen Gesichtern und sie seien nach der tierischen Figur von Stieren oder nach der Raubtiergestalt von Löwen gebildet“76.

Neben dem Einfluss, den die vielgestaltige kulturelle Umgebung auf die Engelsfiguren des Alten Testaments ausübte, wurde eine Verbindung mit anderen Glaubensinhalten auch aus religionspolitischen Gründen forciert: Antike und orientalische Zwischenwesen und Gottheiten, denen - für den Monotheismus

74 Vgl. Hafner, Angelologie, S. 220. Vgl. auch Schart, Der Engelglaube in der biblischen Tradition, S. 47-52.

75 Vgl. Dürr, Der Engel Mächte, S. 30.

76 Pseudo-Dionysius Areopagita, Himmlische Hierarchie, Kapitel 2, § 1. 
hochgradig problematisch - eine eigene Machtsphäre zukam, wurden in Angelologien durch die Figur des Engels integriert, in eine klar definierte Hierarchie (unter Gott stehende und geschaffene Wesen) eingegliedert und semantisch neu besetzt. ${ }^{77}$ Gleichzeitig beförderte diese Verfestigung des Monotheismus aber wiederum das Erstarken von Mittlerwesen. Denn ein konsequenter Monotheismus, der den einen Gott in eine radikale Transzendenz verlagert und jeglicher Wahrnehmbarkeit entzieht, provoziert Zwischenwesen, die die notwendigen Akte der Vermittlung gegenüber der Menschenwelt leisten und einer Art horror vacui der Sphärenordnung entgegenwirken. So stehen „Abstraktion des Gottesbildes und Buntheit des Engelsbildes“"78 in unmittelbarem Zusammenhang. ${ }^{79}$

Auch in der Bibelstelle, die für die Erklärung des Bösen herangezogen wurde, sind Engel als Katalysatoren von Hybridität verwickelt. Sie vermischen sich mit den Menschenfrauen und zeugen Riesen, ein eklatanter Verstoß gegen die von Thomas postulierte Uneigentlichkeit des angelischen Körpers. ${ }^{80}$ Diese Erzählung steht vor der Ankündigung der Sintflut und dient dazu, die verdorbenen Sitten zu veranschaulichen, die eine derart drastische Reaktion Gottes nötig machen:

Als aber die Menschen sich zu mehren begannen auf Erden und ihnen Töchter geboren wurden, da sahen die Gottessöhne, wie schön die Töchter der Menschen waren, und nahmen sich zu Frauen, welche sie wollten. [...] Es waren Riesen zu den Zeiten und auch danach noch auf Erden. Denn als die Gottessöhne zu den Töchtern der Menschen eingingen und sie ihnen Kinder gebaren, wurden daraus Riesen. Das sind die Helden der Vorzeit, die hochberühmten.

(1 Mos 6,1-4)

Bei diesem Stoff handelt es sich um Material, das bereits zur Entstehungszeit der Genesis uralt war. ${ }^{81}$ An dieser Stelle wird der Prozess der Amalgamierung von angeeigneten Fremdgöttern und Engelsvorstellungen besonders deutlich. So zeigt die noch teilweise erhaltene Differenz zwischen den biblischen Engeln und den im Gegensatz zu diesen autonom agierenden „Gottessöhnen“ in der Septuaginta das Bestreben, die außerisraelitischen Gottheiten im Sinne eines doppelten conservare aufzuheben und ältere Glaubensinhalte in den Vorstellungskosmos des Monotheismus zu integrieren. ${ }^{82}$ Bei Philo von Alexandrien

77 Vgl. Dürr, Der Engel Mächte, S. 32-33.

78 Hafner, Angelologie, S. 10.

79 Vgl. Hafner, Angelologie, S. 9-10.

80 Thomas von Aquin löst das Problem, indem er die Gottessöhne nicht zu Engeln, sondern zu Kindern Seths erklärt (vgl. Thomas von Aquin, Summe der Theologie, Prima Pars, Quaestio 51, Artikel 3c).

81 Vgl. Gunkel, Göttinger Handkommentar zum Alten Testament, S. 59.

82 Vgl. Dürr, Der Engel Mächte, S. 22. 
(ca. 25 v. Chr.-50 n. Chr.) und Josephus (37-100) wurde dann die Bezeichnung „Gottessöhne“ durch „Engel Gottes“ substituiert, diese Differenz also eingeebnet. ${ }^{83}$ Dadurch verbanden sich israelitische Glaubensinhalte mit außerisraelitischen Versatzstücken zur Installierung eines klaren und geschichtlich mit dem Fall der Engel erklärten Gut-Böse-Rasters. ${ }^{84}$ Dieses Beispiel verdeutlicht, dass die Figur des Engels eine hybride Integrations- und Homogenisierungsfigur darstellt, über die pagane Glaubensvorstellungen sowie die Möglichkeit des Unreinen als sündiges Abfallen von Gott Eingang in den jüdischen Monotheismus fanden. So wurde im Anschluss an 1 Mos 6,1-4 zwischen den guten und den bösen Engeln unterschieden, deren mit Menschenfrauen gezeugte Nachkommenschaft den Stand der Dämonen bilden. Dass Engel, die anders als Menschen ideale Geschöpfe darstellen, böse werden können, bedeutete eine Verschärfung der Theodizee-Frage, die deshalb ausgiebig in Angelologien thematisiert wurde. ${ }^{85}$

Die Kargheit der skandalträchtigen Erzählung in 1 Mos 6,1-4 führt Hermann Gunkel auf den „hochmythologischen“ und daher „Anstoß“86 erregenden Inhalt zurück. Entsprechend ausgeprägt ist das Bedürfnis, die fehlenden Umstände zu ergänzen, was sich in vielen apokryphen und pseudepigraphischen Texten ausdrückt. Im Buch Henoch etwa sind es die sexuelle Begierde einiger Engel und der sich anschließende, die Welt verderbende Geheimnisverrat, ${ }^{87}$ die das Böse begründen. In Augustinus' De civitate Dei (413-426) bedient der erste, aus Hochmut gefallene Engel sich der Schlange zu teuflischen Einflüsterungen, ${ }^{88}$ und dann lassen sich die Menschenfrauen, immer schon von zweifelhafter Moral, ${ }^{89}$ mit den Bürgern des Himmelstaats ein. Eine andere, teils kombinierte Variante für die Erklärung des Bösen sind Stolz und Hochmut (vgl. Ez 28,12-18; Jes 14,12-15). Dass sich die intensiv rezipierte Erzählung der abtrünnigen Engel vor allem über apokryphe Quellen wie das Buch Henoch und nachfolgende Spekulationen verbreitete und für die gegenwärtige Theologie - anders als für die Popkultur - völlig belanglos ist, ${ }^{90}$ demonstriert die Wirkmacht nichtformalisierten Bibelwissens. ${ }^{91}$ Das Beispiel der gefallenen Engel verdeutlicht zudem, dass die Entwicklungs- und Vermitt-

83 Vgl. Dürr, Der Engel Mächte, S. 22.

84 Vgl. Dürr, Der Engel Mächte, S. 22.

85 Vgl. Hafner, Angelologie, S. 132-133.

86 Gunkel, Göttinger Handkommentar zum Alten Testament, S. 59.

87 Vgl. Das Buch Henoch, hg. von Katja Wolf, Bad Schwartau 2010, S. 22.

$88 \mathrm{Vgl}$. Augustinus, Vom Gottesstaat. Aus dem Lateinischen übertragen von Wilhelm Thimme, München 2007, S. 180-181.

89 Vgl. Augustinus, Vom Gottesstaat, S. 262-263.

90 Vgl. Hafner, Angelologie, S. 145-146.

91 Vgl. Polaschegg, Literarisches Bibelwissen als Herausforderung für die Intertextualitätstheorie, S. 214. 
lungsbewegungen der Engel fortwährend mit ihrer Immaterialität und Gleichförmigkeit in Konflikt geraten und so die ihnen zugeschriebene Reinheit untergraben. Problematisch am Fall der Engel ist weniger die Sünde als vielmehr der Bruch mit der Ordnung, der sich in diesen Überschreitungen ausdrückt.

Diese Spannung, die die Engel kennzeichnet, ist auch geschichtsphilosophisch tragend. Das Attribut der immutabilitas, das aus der Geistigkeit der Engel folgt, ${ }^{92}$ ist eng mit der ihnen zugeschriebenen Reinheit verknüpft. Reinheit wiederum impliziert ahistorische Gleichförmigkeit und Entwicklungslosigkeit. Gälte diese aber universell, so ließe sich der Abfall einiger Engel von Gott nicht erklären und somit auch nicht das Böse in der Welt, will man nicht der aus christlicher Perspektive „giftschwangeren Lehre“93 einer zweiten demiurgischen Instanz sui generis folgen und so den Glauben an das ursprünglich Gute alles Geschaffenen zugunsten eines gnostischen Manichäismus aufgeben. ${ }^{94}$ Böse werden daher die ursprünglich gut geschaffenen Kreaturen durch Abfall von Gott, der aufgrund der „Freiheit des Willens“95 möglich ist. Nach Origenes ist damit keine irreversible Entscheidung getroffen, sondern ein fluktuierender Prozess verbunden, sodass „wir und die Engel in einer künftigen Ordnung Dämonen werden, wenn wir nachgelassen haben, und wiederum Dämonen, wenn sie sich

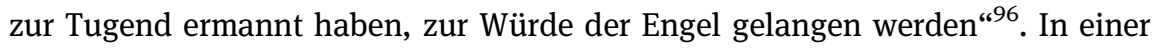
nichtgnostischen Perspektive kann es keinen wesenhaften Unterschied zwischen Engeln und Dämonen geben, Angelologie und Dämonologie sind daher intrinsisch verbunden und spiegelbildlich konstruiert. ${ }^{97}$ Das Böse als Bruch mit der gleichbleibenden Reinheit fungiert als Katalysator von geschichtlicher Entwicklung überhaupt, wobei der Engelsfall den menschlichen Sündenfall vorwegnimmt. Die Engel sind mit ihrer Diffundierung vermeintlich statischer Kategorien und der Möglichkeit des Abfalls von Gott quasi als Träger des veloziferischen Prinzips konstitutiv für historische Zustandsveränderungen.

Engel sind aber nicht nur nötig, um eine widergöttliche Sphäre nichtgnostisch erklären zu können, sie wirken ebenso mit an der Überwindung der historischen Zeit und der Installierung des göttlichen Reichs. So kommt in der eschatologischen

92 Vgl. Heinrich Schmid, Die Dogmatik der evangelisch-lutherischen Kirche, Erlangen 1843, S. 148 sowie Dürr, Der Engel Mächte, S. 95-96.

93 Augustinus, Vom Gottesstaat, S. 22.

94 Vgl. Augustinus, Vom Gottesstaat, S. 22.

95 Origenes, Über die Grundlehren der Glaubenswissenschaft, S. 67.

96 Origenes, Über die Grundlehren der Glaubenswissenschaft, S. 67.

97 Vgl. Rainer Christoph Schwinges, Wider Heiden und Dämonen - Mission im Mittelalter. In: Engel, Teufel und Dämonen. Einblicke in die Geisterwelt des Mittelalters, hg. von Hubert Herkommer u. Rainer Christoph Schwinges, Basel 2006, S. 9-32, hier S. 19. 
Vorstellung mit dem endgültigen Sieg über das Böse auch die geschichtliche Zeit zum Stillstand und das ewige Reich Gottes bricht an. Hier treten die Engel wieder vor allem als Exekutive in Erscheinung: „Und er [der Menschensohn, L.Z.] wird seine Engel senden mit hellen Posaunen, und sie werden seine Auserwählten sammeln von den vier Winden, von einem Ende des Himmels bis zum andern.“ (Mt 24,31) Der Apokalypse liegt strukturell ein dialektisches Verhältnis von irdischer und himmlischer Ordnung, von Mangel und Fülle zugrunde, das geschichtsphilosophisch temporalisiert ist. ${ }^{98}$ Die Gattung der apokalyptischen Schriften (von

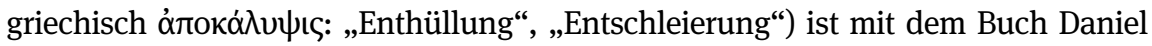
im zweiten vorchristlichen Jahrhundert in der Zeit des babylonischen Exils entstanden und von dessen Leid- und Verfolgungserfahrungen geprägt. ${ }^{99}$ Vor diesem soziopolitischen Krisenhintergrund entstehen Bilder einer fundamentalen Verworfenheit der Welt, die einen irreversiblen Endpunkt markiert, an dem keine immanent-historische Ordnungsstiftung mehr denkbar ist. In der apokalyptischen Dramaturgie erwächst daraus der Umschlag in eine alles überstrahlende Hoffnung. Diese verspricht die ebenfalls jede historische Erfahrung übersteigende überirdische Fülle und Glückseligkeit des himmlischen Reichs.

Die apokalyptische Dramaturgie fußt auf dem Dreiklang einer paradiesischen Vergangenheit, einer mangelhaften Gegenwart und der Hoffnung auf eine erlösende Zukunft. Sie begründet damit das triadische Geschichtsmodell, das das abendländische Weltbild entscheidend prägen wird. Ausgehend von konkreten politischen Phänomenen deutet die apokalyptische Semantik nicht nur die gegenwärtigen Zeichen, sondern wirkt als Interpretationsschlüssel selbst auf die Gestaltung der Zeit zurück, ist also auch in ihrer Entstehungszeit immer schon politisch $\mathrm{zu}$ verstehen. Klaus Vondung unterstreicht diese Verquickung von religiösen und weltlichen Apokalypsen: Religiös-apokalyptische Bewegungen postulierten ein diesseitiges vollkommen-gerechtes Dasein, das durch ein teils militantes Eingreifen des Menschen zu verwirklichen gesucht wurde. ${ }^{100}$ Aus diesem Grund „waren auch die ,religiösen“ Apokalypsen schon immer zugleich ,säkular““101. Umgekehrt sind „die ,säkularisierten“ Apokalypsen der Moderne nicht ohne religiöse Tiefendimension, sowohl in historischer wie in psychischer

98 Vgl. Alexander K. Nagel, Ordnung im Chaos. Zur Systematik apokalyptischer Deutung. In: Apokalypse. Zur Soziologie und Geschichte religiöser Krisenrhetorik, hg. von Alexander K. Nagel, Bernd U. Schipper u. Ansgar Weymann, Frankfurt am Main 2008, S. 49-72, hier S. 55.

99 Vgl. Klaus Vondung, Die Faszination der Apokalypse. In: Apokalypse. Zur Soziologie und Geschichte religiöser Krisenrhetorik, hg. von Alexander K. Nagel, Bernd U. Schipper u. Ansgar Weymann, Frankfurt am Main 2008, S. 177-196, hier S. 177.

100 Vgl. Vondung, Die Faszination der Apokalypse, S. 181.

101 Vondung, Die Faszination der Apokalypse, S. 181. 
Hinsicht“102 . Ein wesentliches Merkmal des apokalyptischen Szenarios liegt in der Transzendierung der realgeschichtlichen Umstände zu einem metaphysisch überhöhten Endkampf zwischen Gut und Böse als der zentralen kosmischen Dichotomie. ${ }^{103}$ Auch in dem apokalyptischen Konflikt, der durch die gute Engelsund die böse Dämonenwelt illustriert wird, nehmen die Engel eine Scharnierfunktion zwischen realpolitischer Auseinandersetzung und transzendenter Axiologie ein. Sie spielen eine tragende Rolle bei der Vermittlung arkanen Wissens und der Projektion einer neuen Weltzeit gegenüber der sündhaften und todesverfallenen Gegenwart. Im Buch Daniel wird in Visionen das Spannungsverhältnis von transzendenter Gottesherrschaft und konkreten geschichtlichen Kräften ausgelotet und universalisiert. So spiegelt sich der Kampf Israels mit dem Heidentum im Kampf von Michael als Schutzengel Israels mit heidnischen Engel-Fürsten im Himmel (vgl. Dan 10,12-21), aus dem dann das ewige Reich Israels hervorgehen wird. Dieser kosmische Gegensatz wird im 20. Jahrhundert im Zusammenhang mit dem Kampf gegen den Nationalsozialismus wieder aufgegriffen. So heißt es bei Klaus Mann: „Die herkömmliche Antithese ,reaktionär-revolutionär hat ihre Schlagkraft und Aktualität verloren angesichts eines Kampfes, in dem weder das Erbe der Vergangenheit noch die Versprechen der Zukunft verschont werden. Der uralte und dennoch frappierend neue Gegensatz, der die überholte politische Antithese ersetzt, ist der zwischen Gut und Böse.“104

In den Angelologien bedeutete die Historisierung des kosmischen Weltgeschehens eine wesentliche Vergrößerung des Funktionsbereichs der Engel, die bis dahin als vergleichsweise konturlose Gefäße der göttlichen Stimme fungierten. ${ }^{105}$ Sie gewinnen nun in ihrer Funktion als Repräsentanten Gottes eine relative Eigenständigkeit, ${ }^{106}$ indem sie die weltlichen Mächte versinnbildlichen und kosmische Kräfte lenken. Klaus Vondung verweist auf die starke Faszination der apokalyptischen Bildersprache, in der zerstörerische Naturgewalten - als deren Personifikationen die Engel dienen - bis heute für die Vergegenwärtigung des Grauens herangezogen werden. ${ }^{107}$ Dass die apokalyptische Semantik, für die ein binäres Denken konstitutiv ist, mit dem Gegensatz von Reinheit und Schmutz

102 Vondung, Die Faszination der Apokalypse, S. 181.

103 Vgl. Ansgar Weymann, Gesellschaft und Apokalypse. In: Apokalypse. Zur Soziologie und Geschichte religiöser Krisenrhetorik, hg. von Alexander K. Nagel, Bernd U. Schipper u. Ansgar Weymann, Frankfurt am Main 2008, S. 13-48, hier S. 14.

104 Klaus Mann, Blut, Schweiß und Tränen. In: Mann, Zweimal Deutschland. Aufsätze, Reden, Kritiken 1938-1942, hg. von Uwe Naumann u. Michael Töteberg, Reinbek 1994, S. 310318, hier S. 317.

105 Vgl. Dürr, Der Engel Mächte, S. 37.

106 Vgl. Dürr, Der Engel Mächte, S. 37.

107 Vgl. Vondung, Die Faszination der Apokalypse, S. 191. 
operiert, lässt sich mit Mary Douglas als weiteres Indiz für die gesellschaftspolitische Verankerung des apokalyptischen Narrativs lesen.

\subsection{Zwischen Tugendideal und Gesellschaftsbedrohung: Das engelsgleiche Leben}

Die angelische Spannung von Reinheit und Hybridität stellt eine Bedrohung für die Logik des Monotheismus dar. Auf individueller Ebene jedoch birgt sie ein Versprechen, das dem Engel als Vorbild für die menschliche Lebensführung ungeheure Attraktivität bescherte. „Schreite fort in den Tugenden, damit du den Engeln gleich werdest“108, fordert der Kirchenvater Basilius von Caesarea in seinem Werk Drei vorläufige ascetische Unterweisungen. Gleichzeitig sind es die Hybridisierung der angelischen Vermittlungsbewegung und die darin enthaltene Überwindung von Grenzen, die die Vorstellung nähren, man könne als Mensch dieses Ideal tatsächlich auch erreichen, also selbst zum Engel werden. Diesem Gedanken ist das wirkmächtig gewordene Schema vom Tier als reinem Körperwesen, dem Engel als reinem Geistwesen und dem Menschen als Mischwesen im Dazwischen unterlegt. Bei Augustinus heißt es dazu:

\footnotetext{
So ist der Mensch ein Mittleres, aber zwischen den Tieren und Engeln. Denn während das Tier ein unvernünftiges und sterbliches Lebewesen ist, der Engel aber ein vernünftiges und unsterbliches, steht der Mensch in der Mitte, tiefer als der Engel und höher als die Tiere, und hat mit den Tieren die Sterblichkeit, mit den Engeln die Vernunft gemeinsam, ist also ein vernünftiges und sterbliches Wesen. ${ }^{109}$
}

Das klingt zunächst recht statisch, an anderer Stelle erklärt Augustinus allerdings, dass die leeren Plätze der gestürzten Engel im Himmel durch Menschen besetzt werden. Diese „sollten einen Ersatz bilden für den Verlust, den die Gesellschaft der Engel durch den Sturz der Teufel erlitten hatte“110, wie Hafner zusammenfasst. Als Figuration anthropologischer Liminalität, als die der Engel gemeinsam mit dem Tier das Definiens des Menschen bildet, kommt ihm eine ungeheure Bedeutung für das menschliche Selbstbild und die Modellierung des eigenen Lebens zu.

Im Lauf des 4. Jahrhunderts avancierten die Engel entsprechend zum Vorbild frühmönchischer Lebensführung mit ethischem wie erkenntnistheoreti-

108 Basilius von Caesarea, Drei vorläufige ascetische Unterweisungen. Ausgewählte Schriften des heiligen Basilius des Grossen. Übersetzt von Dr. Valentin Gröne, Kempten 1877, S. 32.

109 Augustinus, Vom Gottesstaat, S. 446.

110 Hafner, Angelologie, S. 152-153. 
schem Wert, geprägt von Enthaltsamkeit, Wachsamkeit, Bedürfnis- und Affektkontrolle. ${ }^{111}$ Es galt dem Sein der Engel nachzueifern, als dem „der Nahrung nicht bedürftige[n], sondern lediglich sich selbst erhaltende[n], empfindende[n] und erkennende[n] Leben“"112. Die Überschreitung des irdischen Lebens hin zu einem autarken angelischen Sein funktioniert über den Körper. Dem Streben nach dem bios angelikos, dem engelsgleichen Leben, liegt die Vorstellung zugrunde, dass der Körper zum Medium und Zeichen einer die materielle Ebene überschreitenden Wandlung werden kann, wobei diese Semiose sich an vergeistigende Praktiken des physischen Verzichts knüpft. Der Engel ist so Ziel und Medium der Überwindung irdischer Gebundenheit - erreicht werden soll eine spirituelle Reinheit, die über körperliche, androgynisierende Reinigungspraktiken realisiert wird.

Reinheit, mit der besondere Gottesnähe und Vollkommenheit assoziiert wurden, hat eine lange Geschichte als Gegenstand menschlichen Begehrens. Sie verdichtet sich im Bild des Androgynen. So wie Adam und Eva, aber auch andere Urpaare in diversen mythischen Überlieferungen vor dem Sündenfall eine schuldlos-übergeschlechtliche Einheit bildeten, ${ }^{113}$ wird im christlichen Vorstellungskosmos auch der Engel als androgyne Figur gedacht. Die Androgynie wiederum gilt als ein zentrales Attribut des Göttlichen, das bei den Menschen als Strafe für ihre Anmaßung, gottähnlich zu sein, in eine unvollkommene und leidvolle Zwitterhaftigkeit zerbricht. ${ }^{114}$ Androgynie auf menschlicher Ebene ist also einerseits Sinnbild der Überwindung irdischer Mängel, steht andererseits aber immer auch unter HybrisVerdacht. Zentral für die antizipierte engelsgleiche Androgynität ist der Gedanke der sexuellen Abstinenz, die Engeln zugeschrieben wurde. ${ }^{115}$ Der Begriff der Jungfräulichkeit (virginitas) hatte dabei einen sehr viel weiteren Bedeutungsspielraum als dies heute der Fall ist. Spirituell ausgerichtet bezeichnete er allgemein ein Leben, das sich nicht in irdische Begrenzungen fügt, sondern durch umfassende Enthaltsamkeit und Tugendhaftigkeit zum Spiegel der göttlichen Sphäre wird. ${ }^{116}$

111 Besonders ausgeprägt ist die Rolle des Engels als Veranschaulichung vorbildlicher Lebensführung in den Schriften des Kirchenvaters Gregor von Nyssa; dazu Matthias Hoch, ,Reinheit‘ und ,Ordnung'. Leibliches und seelisches Dasein in den Schriften de virginitate, vita Sanctae Macrinae, de anima et resurrectione, de hominis opificio und de oratio catechetica magna des Gregor von Nyssa, Hamburg 2013, S. 246-250.

112 Augustinus, Vom Gottesstaat, S. 382.

113 Vgl. Mircea Eliade, Die Religionen und das Heilige, Darmstadt 1976, S. 479-480.

114 Vgl. Armin Strohmeyr, Traum und Trauma. Der androgyne Geschwisterkomplex im Werk Klaus Manns, Augsburg 1997, S. 486.

115 Vgl. Peter Brown, Die Keuschheit der Engel. Sexuelle Entsagung, Askese und Körperlichkeit am Anfang des Christentums, München; Wien 1991, S. 202.

116 Vgl. Brown, Die Keuschheit der Engel, S. 54-55. 
Nach Peter Brown korrelierte dem Aufstieg der christlichen Kirche im 3. Jahrhundert eine „,Ästhetik‘ der Jungfräulichkeit“117 mit dem unberührten Körper als Ausgangspunkt, in dem sich himmlische und irdische Ordnung kreuzten und eine aufstrebende Institution ihr symbolisches Zentrum erhielt. ${ }^{118}$ Dieses spannungsreiche Ineinander von Irdischem und Himmlischem hat nicht nur einen ontologischen und ästhetischen, sondern auch einen temporalen Index. Denn gegenläufig zur postlapsarischen irdischen Gegenwart gilt die himmlische Sphäre als Hort einer verlorenen wie einer noch ausstehenden asexuellen Seligkeit, die die Engel bereits erreicht haben:

Und Jesus sprach zu ihnen: Die Kinder dieser Welt heiraten und lassen sich heiraten; welche aber gewürdigt werden, jene Welt zu erlangen und die Auferstehung von den Toten, die werden weder heiraten noch sich heiraten lassen. Denn sie können hinfort nicht sterben; denn sie sind den Engeln gleich und Gottes Kinder, weil sie Kinder der Auferstehung sind.

(Lk 20,34-36)

Die jungfräuliche Existenz verbindet die scheinbar isolierten Zustände von irdischem und überirdischem Leben. Denn sie ahmt nicht nur die Reinheit der Engel nach, sondern nimmt diese auf Erden vorweg. Der engelsgleich lebende Mensch erfährt so bereits in der Gegenwart einen Vorgeschmack jenes Himmelsbürgerdaseins, das ihn nach der Auferstehung erwartet. ${ }^{119}$ Darin liegt eine Besonderheit des christlichen Denkens gegenüber dem jüdischen, das Zeitverkürzungen in dieser Hinsicht nicht kennt. ${ }^{120}$

Mit der temporalen Verschiebung eignet der asketisch-jungfräuliche Mensch sich nicht nur die Reinheit der Engel an, sondern auch ihre Medialität. Indem der Körper in seiner Enthobenheit gegenüber dem Fluss sexueller Zirkulation - wie der Engel zeugt die Jungfrau keine Kinder - zu einem Bildnis vollkommener Integrität und Unversehrtheit avanciert, wird er zum Symbol transzendiert: Er ist nicht länger durch biologische Reproduktionsprozesse gebunden, die die Hinfälligkeit irdischen Seins anzeigen, sondern frei für eine Resemantisierung als irdischer Spiegel engelhafter Reinheit. Als solcher wird er zum Bollwerk gegen heidnische Kontamination und zum irdischen Vorschein der jenseitigen Ewigkeit.

117 Brown, Die Keuschheit der Engel, S. 154.

118 Vgl. Brown, Die Keuschheit der Engel, S. 154.

119 Vgl. Frank, Angelikos Bios, S. 57-59. Diese Verknüpfung mit dem (ewigen) Leben muss auch vor dem Hintergrund gelesen werden, dass Sexualität in einer Zeit hoher Kinder- und Müttersterblichkeit oft mit dem Tod assoziiert wurde (vgl. Hoch, ,Reinheit' und ,Ordnung', S. 30). Dass dieser Zustand empfängnisloser Unbeflecktheit gleichwohl prekär ist, zeigt sich in der Gefahr des Engelfalls bzw. in den rigorosen gesellschaftlichen Schutzvorrichtungen zur Bewahrung der Jungfräulichkeit.

120 Vgl. Pikulik, Warten, Erwartung, S. 23. 
Wie bei den reingeistigen Engeln stellt sich auch hier die Frage, wie die spirituell fundierte Jungfräulichkeit anschaulich werden kann. Als Spieleinsatz und Ausdrucksmedium zugleich fungiert ein von Nahrungsrestriktion gezeichneter Körper, der abgemagert und unfruchtbar ist. Im Zwischenreich von physischem Tod und geistig-ewigem Leben ist dieser immer auf dem Sprung, die konstitutive Trennung von leiblich-endlicher und geistig-ewiger Sphäre zu überschreiten. Analog zur sexuellen Abstinenz bedeutet die Nahrungsaskese ebenfalls eine mit Reinheit konnotierte und Androgynität antizipierende Zäsur im Reproduktionskreislauf. Sexuelle und nutritive Enthaltsamkeit machen in ihrer Überwindung nicht nur körperliche, sondern vor allem auch geschlechtliche Grenzen hinfällig. Wird der die geschlechtliche Differenz zementierende sexuelle Akt verweigert und lässt das Hungern gleichzeitig geschlechtsspezifische Körperformen bis zur Unfruchtbarkeit schwinden, dann entsteht eine Uneindeutigkeit, die eine vor- beziehungsweise übergeschlechtliche Vollkommenheit suggeriert. ${ }^{121}$ In ihr, so die Vorstellung, ist der Bruch des Sündenfalls aufgehoben.

Peter Brown verweist darauf, dass insbesondere in Gesellschaften, in denen eine rigorose Geschlechtertrennung herrschte, die Überwindung dieser Beschränkungen die befreiende Wirkung der christlichen Religion besonders zu akzentuieren vermochte. ${ }^{122}$ Hier ist eine Spannung festzuhalten zwischen der Zementierung der männlich dominierten Gesellschaftsform, die das auch für die Frau gültige Ideal installierte, und der Möglichkeit, aufgrund des vormodernen Eingeschlechtermodells die eigene Lebensform durch den Austritt aus dem Frau-Sein auf das Ideal kontrollierter Männlichkeit hin zu überschreiten. ${ }^{123}$ Nach Basilius von Caesarea hin-

121 Vgl. Brown, Die Keuschheit der Engel, S. 341.

122 Vgl. die Beschreibung von Peter Brown: „In Syrien und in Gegenden, die von syrischen Formen des Asketizismus berührt waren, waren Geschichten von Frauen in Umlauf, die aus ihrer sexuellen Identität ausgestiegen waren. Sie hatten ihren Körper durch langes Fasten zu einer ,engelhaften “ Unbestimmtheit gebracht. Sie hatten sich das Haar abgeschnitten. Sie hatten sogar Männerkleidung angenommen, um frei durch die bewohnte Welt zu wandern“ (Brown, Die Keuschheit der Engel, S. 341). Zum Aspekt von Askese und Geschlechtlichkeit vgl. Ruth Albrecht, Zum Ideal der Überwindung der Geschlechterdifferenz in der spätantiken christlichen Askese. In: Askese. Geschlecht und Geschichte der Selbstdisziplinierung, hg. von Irmela Marei Krüger-Fürhoff u. Tanja Nusser, Bielefeld 2005, S. 17-42 sowie Waltraud Pulz, Askese, Charisma oder Krankheit? Bedeutungen und Funktionen frühzeitlicher ,Fastenwunder'. In: Askese. Geschlecht und Geschichte der Selbstdisziplinierung, hg. von Irmela Marei Krüger-Fürhoff u. Tanja Nusser, Bielefeld 2005, S. 43-54, hier S. 52.

123 Diese unaufhebbare Uneindeutigkeit, die sich einem dichotomischen Denken verweigert, verorten die Künstlerinnen Maria Klonaris und Katerina Thomadaki in der Intersexualität, die sie mit dem Engel verbinden: „Bei unseren Überlegungen rund um das Geschlecht stießen wir nach und nach zur intersexuellen Gestalt vor, zum ,Engel', denn er verkörpert die radikalste Position: keine Synthese, keine Umkehrung, sondern ein unfaßbares Zwischen-den-Beiden“ 
ken allerdings asketisch lebende Frauen wegen ihres Körpers auf den Stufen der Engelsannäherung Männern immer einen entscheidenden Schritt hinterher:

So muss die Jungfräulichkeit im Übrigen als etwas Großes und Herrliches verstanden werden; und was die Auferstehung und das unvergängliche Leben betrifft, so zeigt sie sich von nun an als reiner Keim. Denn wenn „in der Auferstehung weder Männer Frauen noch Frauen Männer nehmen, sondern wie Engel sind“ und „Söhne Gottes“ sein werden, sind diejenigen, die ihre Jungfräulichkeit bewahren, Engel, die mit einem Fleisch ohne Verderbnis durch das menschliche Leben gehen; Engel 〈nicht〉 unklar, sondern ganz und gar sichtbar. [...] 〈Und〉 ebenso wie diese durch die Enthaltsamkeit in ihrem Mannsein in den Rang von Engeln erhoben wurden, so gilt das Gleiche für sie, die durch eine gleiche Enthaltsamkeit in ihrem Frausein in den gleichen Rang wie jene erhoben wurden, und so im gegenwärtigen Leben den Männern hinsichtlich der Seele gleichgestellt sind, aber von einer Gleichheit, die wegen des weiblichen Körpers, der sie bekleidet, falsch ist, während sie dank der Tugend im zukünftigen Leben den Männern in allem gleich geworden sind. ${ }^{124}$

Mittel und Krux der Angelisierung ist also der weibliche Körper. Mit Mary Douglas, die die gesteigerte Relevanz von Körperöffnungen für eine ordnungsstiftende Symbolbildung betont, wird deutlich, wie im frühen Christentum sexuelle Restriktionen für Operationen des Ein- und Ausschließens genutzt wurden. Ausgangspunkt ist zunächst der universelle Anspruch des Christentums, der auf die gesamte Menschheit zielt:

Denn ihr seid alle durch den Glauben Gottes Kinder in Christus Jesus. Denn ihr alle, die ihr auf Christus getauft seid, habt Christus angezogen. Hier ist nicht Jude noch Grieche, hier ist nicht Sklave noch Freier, hier ist nicht Mann noch Frau; denn ihr seid allesamt einer in Christus Jesus.

(Gal 3,26-28)

(Maria Klonaris u. Katerina Thomadaki, Dem Geschlecht nicht unterworfen. Ein Manifest [Auszug]. In: Engel, :Engel. Legenden der Gegenwart, hg. von Cathrin Pichler, Wien 1997, S. 282285, hier S. 283-284).

124 Basilius von Caesarea, De virginitate de Saint Basile. Texte vieux-slave et trad. française par A. Vaillant, Paris 1942, S. 57-59 [meine Übersetzung, L.Z.]. Im Original: „Ainsi, pour tout le reste, la virginité doit être comprise comme chose grande et superbe; et quand à la résurrection et à la vie incorruptible, elle s'en montre dès maintenant un germe pur. Car si à la résurrection les hommes ne prennent pas de femmes ni les femmes d'hommes, mais ils sont comme des anges“ et seront ,fils de Dieu', ceux qui gardent leur virginité sont des anges, parcourant la vie humaine avec une chair sans corruption; et des anges 〈non〉 obscurs, mais tout à fait en vue. [...] $\langle E t\rangle$ de même que ceux-ci sont passés par la continence de l'état d'hommes au rang des anges, il en est de même pour elles, qui sont passées grâce à une continence égale à la leur de l'état de femmes au mêmes rang qu'eux, étant dans la vie présente égales aux hommes quant à l'âme, mais d'une égalité qui cloche du fait du corps féminin qui les revêt, tandis que dans la vie future on les trouve devenues les égales en tout des hommes grâce à la vertu.“ 
Angesichts der tatsächlichen Heterogenität der christlichen Gruppen zu dieser Zeit kann die regulierte Sexualität Identität und Einheit stiften. ${ }^{125}$ Das geschieht, indem sie alle geschlechtlichen und gesellschaftlichen Grenzen überschreitet, gleichzeitig aber faktisch über das postulierte Ideal reiner Jungfräulichkeit andere kulturelle und religiöse Strömungen ausschließt. Allerdings ist diese Einheit mit einer enormen Sprengkraft erkauft, da die Ablehnung weltlicher Ordnung die Grundfeste von Gesellschaften, die gerade auf der Ungleichheit von Herr und Sklave, Mann und Frau aufbauten, in Frage stellt. Nicht ohne Grund schreibt Mary Douglas über die Zwischenräume, in denen die Engel zu Hause sind, sie seien „per se gefährlich“126, weil sie die ordnungskonstitutiven Grenzen aufweichen. So stehen Basilius und seinem Askese-Konzept, das männliche und weibliche Asketen räumlich voneinander trennt, jene radikalen Formen entgegen, bei denen Frauen und Männer gemeinsam und ohne festen Wohnsitz bettelnd umherziehen und dabei mit sämtlichen sozialen Normen brechen. ${ }^{127}$ Die Entsagung kann so, wie im Hungerstreik, zu einer Form des Protests werden, der sich des eigenen Körpers als Zeichen des Dissens bedient. Ordnung, die sich über akkurate Klassifizierungsoperationen bildet, wird hier durch die Transgression der Grenze zwischen Körper und Geist, Weiblichem und Männlichem bedroht. So ist es bezeichnend, dass gerade über die Frage der Askese kirchliche Machtansprüche ausgetragen wurden, bei denen sich die Zuschreibungen von Orthodoxie und Häresie im Laufe der Zeit änderten. ${ }^{128}$

Soll es mit der gesellschaftlichen Ordnung kompatibel sein, muss das engelsgleiche Leben entweder grundlegende Differenzen wie die von Mann und Frau unangetastet lassen oder es darf nur von einer Minderheit praktiziert werden. Denn Arbeits- und Nahrungsverweigerung sowie sexuelle Enthaltsamkeit als konsequent und flächendeckend betriebene Verweigerung von Reproduktion würden die Selbsterhaltungsprozesse sozialer Systeme massiv beeinträchtigen. ${ }^{129}$ An diesem Punkt wird deutlich, dass die Askese als eine tolerierte, teils bewunderte, teils auch (religions-)politisch instrumentalisierte Lebensform nur möglich ist, wenn die Kontinuität der Gemeinschaft nicht gefährdet ist. ${ }^{130}$ Neben ihrer Sprengkraft hinsichtlich der menschlichen Ordnung bedrohen asketische Prakti-

125 Vgl. Brown, Die Keuschheit der Engel, S. 75.

126 Douglas, Reinheit und Gefährdung, S. 179.

127 Vgl. Susanna Elm, „Schon auf Erden Engel“. Einige Bemerkungen zu den Anfängen asketischer Gemeinschaften in Kleinasien. In: Historia: Zeitschrift für Alte Geschichte, 45/4, 1996, S. 483-500, hier S. 498.

128 Vgl. Elm, „Schon auf Erden Engel“, S. 486.

129 Vgl. Achim Aurnhammer, Androgynie. Studien zu einem Motiv in der europäischen Literatur, Köln; Wien 1986, S. 31.

130 Zur religionspolitischen Instrumentalisierung (weiblicher) Askese vgl. Pulz, Askese, Charisma oder Krankheit?, S. 46-47 u. S. 53. 
ken auch die Differenz zwischen Gott und Mensch. So führt die Abtötung menschlicher Bedürfnisse zu einer autonomen Haltung, die sich einer autopoietischen Modellierung des eigenen Selbst und damit der Hybris der deificatio verdankt - „[d]as asketische Subjekt schafft sich selbst und wird durch diesen Schöpfungsakt zum Rivalen Gottes, zum Autor im emphatischen Sinne““131. Dieser Gedanke vom Menschen als einem Künstler erhält Auftrieb durch die Entleerung der menschlichen Mitte zwischen Tier und Engel. So spricht Gott bei Pico della Mirandola Adam mit folgenden Worten an:

Wir haben dir keinen festen Wohnsitz gegeben, Adam, kein eigenes Aussehen noch irgendeine besondere Gabe, damit du den Wohnsitz, das Aussehen und die Gaben, die du selbst dir ausersiehst, entsprechend deinem Wunsch und Entschluß habest und besitzest. [...] Weder haben wir dich himmlisch noch irdisch, weder sterblich noch unsterblich geschaffen, damit du wie dein eigener, in Ehre frei entscheidender, schöpferischer Bildhauer dich selbst zu der Gestalt ausformst, die du bevorzugst. [...] Im Menschen sind bei seiner Geburt von Gottvater vielerlei Samen und Keime für jede Lebensform angelegt; welche ein jeder hegt und pflegt, die werden heranwachsen und ihre Früchte in ihm tragen. Sind es pflanzliche, wird er zur Pflanze, sind es sinnliche, zum Tier werden. Sind es Keime der Vernunft, wird er sich zu einem himmlischen Lebewesen entwickeln; sind es geistige, wird er ein Engel sein und Gottes Sohn. ${ }^{132}$

Während Pico della Mirandola im 15. Jahrhundert die in der Wahlfreiheit begründete Würde des Menschen ohne jede Zurückhaltung als ausdrücklichen Wunsch Gottes formuliert, liegt darin für spätantike christliche Gesellschaften ein kritisches, ja bedrohliches Element. Die Ambivalenz von Tugendideal und Gesellschaftsbedrohung, die die asketische Existenz ausmacht, findet sich auch auf Seiten des angelischen Vorbilds. So erscheint der Engel bei Basilius als androzentrisches Paradigma, in dem eine maßlose weibliche Sexualität beherrscht

131 Christine Schmider, Visionen der Askese. Orgiastisches Schreiben bei Gustave Flaubert. In: Askese. Geschlecht und Geschichte der Selbstdisziplinierung, hg. von Irmela Marei KrügerFürhoff u. Tanja Nusser, Bielefeld 2005, S. 116-132, hier S. 124. An dieser Stelle ist auch ein Übergangsmoment der Umstellung von einem religiösen zu einem ästhetischer Bezugssystem auszumachen - während der religiösen Askese die Gefahr der selbstherrlichen Anmaßung eingeschrieben ist, zielen moderne Askese-Praktiken auf Ästhetisierung, Disziplinierung und Selbstoptimierung. Auch wenn die sozioökonomischen und kultursymbolischen Brüche der geschichtlichen Entwicklung zu betonen sind, ist die Figur des Engels im Kontext asketischandrogyner Praktiken eine Konstante, deren Wirkmächtigkeit sich nicht auf das Konzept des

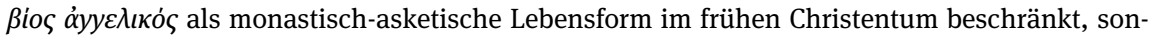
dern bis in die Gegenwart fortwirkt. So stellt der Engel eine zentrale Identifikationsfigur des Anorexie-Diskurses dar, für den ebenfalls Vorstellungen von Androgynie, ätherischer Reinheit und paradiesischer Asexualität konstitutiv sind.

132 Giovanni Pico della Mirandola, De hominis dignitate. Über die Würde des Menschen, hg. von August Buck, Hamburg 1990, S. 5-7. 
ist, die übrigens auch jüdische und pagane Gemeinschaften als regulierungsbedürftig ansahen. ${ }^{133}$ Gleichwohl ist auch hier wieder das den Engel auszeichnende Spannungsmoment von Spiritualität und Materialität zu vermerken, das ihn als unstimmige Figur charakterisiert. So ruft er neben der körperfeindlichen Hypostasierung des Geistes und den Praktiken des Mangels in seiner ikonischen Dimension eine Ästhetik des Überflusses auf.

Wie der unsichtbare Gott ist auch eine abstrakte Reinheitsvorstellung auf erfahrbare Repräsentationen angewiesen, um wirkmächtig zu sein. Der Mangel ruft die Phantasie des Begehrens allererst hervor, die Gestalt des Androgynen als Inversionsfigur oszilliert zwischen Defizienz und Überfluss. Entsprechend sind Engel gerade in ihrer Androgynie erotisch attraktiv gestaltet und die scheinbar asexuelle Androgynie kann jederzeit in eine überbordende Sexualität umschlagen. ${ }^{134}$ Dieser Umschlag manifestiert sich im luziferischen Fall, in dem die mit Reinheit verbundene angelische Übergeschlechtlichkeit gebrochen und verkehrt wird in eine potenzierte, männliche und weibliche Verführungskraft in sich begreifende Sexualität. Die Androgynie des Engels, die göttliche Vollkommenheit suggeriert, ist folglich eine weitere Facette mit der die Engelsfigur das monotheistische Weltbild bedroht. Sie steht für die ambivalente Haltung der Engel zur Ordnung, die im 20. Jahrhundert vielfach aufgegriffen und abgewandelt wird. Die Gefahr des Ordnungsbruchs manifestiert sich im gefallenen Engel, während sie in der Reinheit der konformen Engel abgespalten und im Modus des eingeschlossenen Ausschlusses latent präsent bleibt. Allerdings ist auch in diesen die Ästhetik selbst bereits ein potentielles Einfallstor für häretisches Verhalten.

\subsection{Angelische (Anti-)Ästhetik}

Engel versinnlichen einen Gott, der nicht direkt erfahrbar ist. Sie sind damit genuin aisthetische Figuren. Neben der Überbringung konkreter Botschaften dient ihre Erscheinung dem Zweck, die göttliche Unsichtbarkeit zu kompensieren. Wie intrikat die von den Engeln geleistete Übersetzung von etwas grundsätzlich sinnlich Nichtwahrnehmbarem ist, macht das Programm von Pseudo-Dionysius' Himmlischer Hierarchie deutlich:

133 Peter Brown verweist darauf, dass die sexuelle Regulierung auch und wesentlich auf die Kontrolle der als bedrohlich und schädlich empfundenen Frau abzielte und sich dieses Bestreben nicht auf christliche Gruppen beschränkte, sondern ebenso für jüdische oder pagane Gemeinschaften charakteristisch war (vgl. Brown, Die Keuschheit der Engel, S. 52).

134 Zur erotischen Attraktivität der Androgynigät vgl. Strohmeyr, Traum und Trauma, S. 276. 
Die von ihnen [den heiligsten Schriften, L.Z.] auf sinnbildlichem und anagogischem Wege uns geoffenbarten Hierarchien der himmlischen Geister wollen wir, soweit es in unserer Macht liegt, zu schauen suchen, die ursprüngliche und überursprüngliche Lichtergießung des urgöttlichen Vaters (welche uns die seligsten Hierarchien der Engel in bildlich geformten Zeichen offenbart), mit immateriellen und zuckungsfreien Augen des Geistes aufnehmen und dann hinwieder von ihr aus zu ihrem einfachen Strahl uns erheben. ${ }^{135}$

In der Wendung von den „immateriellen und zuckungsfreien Augen des Geistes“ kulminiert das Paradox, mit dem die gesamte Himmlische Hierarchie fertigzuwerden versucht: die Annahme einer aller Sinnlichkeit enthobenen Vergeistigung, deren Superlative in gleißende Bilder gekleidet werden, um wahrnehmbar zu sein, und die entsprechend eine hyperästhetische Aufnahmefähigkeit verlangt, welche aber eine reingeistige bleiben soll. Als unähnlich-ähnliche Abbilder im Dienst der göttlichen Schönheit fungieren die Engelshierarchien als ästhetische Stützpfeiler dieser Konstruktion. ${ }^{136}$ Dabei werden sie nicht nur argumentativ außerordentlich strapaziert; die Engelsbilder, die der Offenbarung des „urgöttlichen Vaters" dienen, stellen auch eine weitere Form der Ordnungsbedrohung dar.

Der Grund dafür liegt im sinnlichen Überschuss der Angelophanie. Die ästhetische Intensität der Engelserscheinung beinhaltet immer auch die Gefahr, dass die mediale Funktion des Engels, die darin besteht, die göttliche Botschaft zu vermitteln, zurücktritt hinter eine selbstzweckhafte Wahrnehmung der Erscheinung an sich. Diese intransitiv-ästhetische Qualität wird im Kontext eines Hierarchie- und Verweisungssystems problematisch. Denn in diesem ist die Erscheinung der Engel kein Selbstzweck, sondern dient der Kommunikation der göttlichen Botschaft. So befindet Hans Robert Jauß allgemein über die ästhetische Erfahrung:

Vom Standpunkt der religiösen Autorität aus gesehen muß die ästhetische Erfahrung ständig in den Verdacht der Unbotmäßigkeit geraten: wo sie in den Dienst genommen wird, um eine übersinnliche Bedeutung zu vergegenwärtigen, macht sie zugleich die sinnliche Erscheinung vollkommen und bereitet den Genuß erfüllter Gegenwart. ${ }^{137}$

Als Figur einer ästhetischen Erfahrung tritt der Engel in der Bibel teils überaus effektvoll auf, etwa am Grab Jesu: „Seine Erscheinung war wie der Blitz und sein Gewand weiß wie der Schnee.“ (Mt 28,2) Die Überwältigungsästhetik des Engels hat den Zweck, die übermenschliche Tragweite des göttlichen Handelns

135 Pseudo-Dionysius Areopagita, Himmlische Hierarchie, Kapitel 1, § 2.

136 Vgl. Pseudo-Dionysius Areopagita, Himmlische Hierarchie, Kapitel 3, § 2.

137 Hans Robert Jauß, Ästhetische Erfahrung und literarische Hermeneutik, Frankfurt am Main 1982, S. 32. 
zu illustrieren, sie verleitet aber zugleich dazu, die Gott geschuldete Wertschätzung und Ehrfurcht auf den Engel zu übertragen.

In der ästhetischen Dimension der Engel liegt also der Kern ihres zutiefst ambivalenten Verhältnisses zur Macht begründet. Als Repräsentanten der göttlichen Ordnung stellen sie die bildliche Kristallisation von Herrschaftsstrukturen dar, deren ästhetische Verflüssigung sie gleichzeitig bewirken. Die Engel sind nicht nur - und hier weicht diese Studie von Agambens Verständnis ab „die Verkörperung der Weltregierung schlechthin“"138, sie duplizieren nicht in einem reinen Abbildverhältnis die göttliche Botschaft im Bereich des menschlichen Seins, sondern schaffen mit ihrer kaleidoskopischen Erscheinung immer auch eine Änderung und Erweiterung des göttlichen Ursprungs. Engel verkörpern in sich bereits Bildhaftigkeit, da das Verhältnis von Gott und Menschen, deren Kommunikation die Engel durch ihre Erscheinung etablieren, selbst ein genuin bildliches ist. Gott hat den Menschen nach seinem Ebenbild geschaffen (vgl. 1 Mos 1,27) und das menschliche Leben als Streben zum Guten (oder Abfall davon) ist über Ähnlichkeits- und Abbildrelationen vermittelt, messbar an dem „Fortschritte in der Gottähnlichkeit“139, wie es bei Origenes heißt.

Da der göttliche Ursprung als absolutes Sein für den beschränkten Menschen weder unmittelbar noch zur Gänze einsehbar ist, bedarf es des angelischen Bedeutungsträgers, der die Urbild-Abbild-Relation aisthetisiert. Diese Dimension blendet Agamben in Herrschaft und Herrlichkeit aus, wenn er das Ästhetische zweifach verengt: auf ein nachträgliches Verfahren und auf den Begriff des Schönen. Bei „dem schrecklichen Erscheinen YHWH [...], dem Reich, dem Gericht, dem Thron“ handle es sich um „Dinge, die nur einer ästhetisierenden Betrachtungsweise ,schön“ erscheinen können“"140. Der hier veranschlagte Ästhetikbegriff ist dagegen sehr viel weiter gefasst und setzt bei der aisthetischen Dimension des Engels an. Nur so wird die ästhetisch fundierte Ambivalenz der Macht sichtbar, die die Engel stützen und zugleich schleichend unterhöhlen.

Neben ihrer ästhetischen Dimension als solcher ist auch die genaue Beschaffenheit der sinnlichen Erscheinung der Engel problematisch - wie lässt sich Unsinnlichkeit am besten darstellen? Im Zusammenhang mit der den Engeln zugeschriebenen Reinheit wurde bereits das Spannungsverhältnis von körper- und schwerelosen Geistwesen und ostentativer Korporalität thematisiert, das für die Engelserscheinungen in der Bibel und mehr noch ihre späteren Dar-

138 Agamben, Herrschaft und Herrlichkeit, S. 198.

139 Origenes, Über die Grundlehren der Glaubenswissenschaft, S. 64.

140 Agamben, Herrschaft und Herrlichkeit, S. 238. 
stellungen charakteristisch ist. ${ }^{141}$ Über die Engelsfigur wird so der Dualismus von Geist und Körper reproduziert und in der Art ihrer wechselseitigen Verwiesenheit zugleich überschritten. Jede Darstellung von Engeln potenziert das Paradox, das in Pseudo-Dionysius' Schilderung der Offenbarung deutlich wird: Engeln wird Idealität, Schönheit und Vollkommenheit in einem rein intelligiblen, nichtperzeptiven Sinn zugesprochen, man ist aber bei der Vergegenwärtigung dieser Attribute immer auf eine sinnlich erfassbare Darstellung verwiesen. Umgekehrt stiftet der Fluchtpunkt des reinen Geistes die Legitimationsgrundlage für die Darstellung physischer Schönheit. Wie im Fall des engelsgleichen Lebens wird der Körper hier als Ort einer transzendenten Semiose zugleich ab- und aufgewertet. Die ,eigentliche“ Beschaffenheit des Engels ist immer nur im Moment seiner stofflichen Verdichtung als uneigentliche für den Menschen zu erfassen, sein intelligibles Sein an sich ist nicht wahrnehmbar. Dass als Schablone seiner Darstellung der poetisierte menschliche Körper herangezogen wird, führt Pseudo-Dionysius auf das beschränkte menschliche Erkenntnisvermögen zurück:

Denn ganz natürlich hat sich die Offenbarung bei den gestaltlosen Geistern der dichterischen heiligen Gebilde bedient, weil sie, wie gesagt, auf unser Erkenntnisvermögen Rücksicht nahm und für die ihm entsprechende und naturgemäße Emporführung Fürsorge trug und in Anpassung an dasselbe die anagogischen heiligen Darstellungen aufbildete. ${ }^{142}$

Engel sind also bereits in der Bibel Kunstprodukte, so lässt sich zugespitzt formulieren. Die poetische Textur des Engelsbilds ist dabei eng mit seiner Anthropomorphisierung verbunden. In der Kontinuität der Wesenshierarchie verkörpern Engel den Fluchtpunkt der Perfektion. Oft sind es gewellte Haare, zarte, aber starke Gliedmaßen und ein selbstvergessener Blick, die auf die eigentliche Zugehörigkeit zum geistigen Bereich verweisen sollen, tatsächlich aber Aufschluss geben über eine ganz und gar irdische Körperästhetik. Bereits deren vermeintliche Reinheit wird durch das Attribut der Flügel unterwandert, das in der Bibel gewöhnlichen Botenengeln nicht zukommt. Es entstammt der paganen Ikonographie und wird

141 Ohne an dieser Stelle näher auf die kunstgeschichtliche Entwicklung eingehen zu können, ist der Wandel der geschlechtlichen Prägung der Engel bemerkenswert - dominierten in den Engelsdarstellungen anfangs männliche Attributen, so werden Engel ab dem 12. Jahrhundert verstärkt mit androgynen, infantilen oder weiblichen Eigenschaften abgebildet (vgl. Hobson, Angels of Modernism, S. 20-21). Neda Bei verweist in diesem Zusammenhang auf das grundsätzlich Problematische einer geschlechtlichen Zuordnung äußerer Eigenschaften, da diese sich wandelnden historischen Konventionen und Sehgewohnheiten unterworfen sind (vgl. Neda Bei, Die schreckliche Ubiquität der Engel. In: Engel, :Engel. Legenden der Gegenwart, hg. von Cathrin Pichler, Wien 1997, S. 33-50, hier S. 35-36).

142 Pseudo-Dionysius Areopagita, Himmlische Hierarchie, Kapitel 2, § 1. 
erst später zu einem wesentlichen Erkennungsmerkmal der Engel - ein weiterer Beleg für die angelische Hybridität und die Produktivität des Engels als biblisches Sekundärphänomen.

Diese latente Hybridität tritt offen zutage in der Beschreibung der Cherubim und Seraphim im Alten Testament, die mit dem menschlichen Idealtypus denkbar heftig kollidiert. Denn diese Wesen präsentieren sich nicht als Projektionen übermenschlicher Schönheit, sondern als Figurationen radikaler Alterität. Dass Cherubim selten gemäß ihrer vielköpfig-tierischen Charakteristika abgebildet werden, hängt mutmaßlich nicht nur mit ihrer unansehnlichen, sondern schlicht unanschaulichen Beschreibung in Ezechiels Vision zusammen, die sich der Visualisierung tendenziell widersetzt. Neben der praktischen Herausforderung, die die Darstellung der Cherubim mit ihrem Ineinander von mit Augen bedeckten Rädern, die sich gleichzeitig in alle Richtungen bewegen, und den Gesichtern von Cherub, Mensch, Löwe und Adler bedeutet (vgl. Ez 1,5-21), bringen die entsprechenden Bibelstellen auch Pseudo-Dionysius' Identifikation der Engel mit Spiegeln göttlicher Schönheit in arge Bedrängnis. So wie die strahlende Erscheinung erklärt er auch diese „Mißgestalt“ der biblischen Bilder mit den Beschränkungen des menschlichen Geistes:

\begin{abstract}
Denn es ist natürlich, daß man bei den ehrenvolleren heiligen Bildern auch abirre und auf die Meinung kommt, es seien die himmlischen Wesen sozusagen goldartige Männer, lichtgestaltet, funkelnd, von herrlicher Schönheit, in schimmerndes Gewand gekleidet und ohne zu schaden feurig blitzend, oder irgendwelche ähnlich gebildete Figuren, in welchen sonst noch die Offenbarung die himmlischen Geister äußerlich dargestellt hat. Um nun diejenigen, welche keine höhere Schönheit kennen als die äußerlich erscheinende, vor diesem Fehler zu bewahren, läßt sich die anagogische Weisheit der heiligen Verfasser der Offenbarungsschriften auch zu den unpassenden Unähnlichkeiten heilig herab und duldet nicht, daß der sinnliche Teil in uns an den unedlen Bildern haften bleibe und in ihnen ruhe. Sie regt vielmehr das Höhere der Seele an und stachelt sie durch die Mißgestalt der entworfenen Bilder auf, da es ja selbst den ganz fleischlichen Menschen nicht zulässig und wahr zu sein scheint, daß diesen so häßlichen Dingen die überhimmlischen und göttlichen Erkenntnisobjekte in Wirklichkeit ähnlich sind. ${ }^{143}$
\end{abstract}

Über das Abwegige der nicht bloß un-, sondern dezidiert antiästhetischen Engel soll nicht nur ihrer idolatrischen Verehrung vorgebeugt, sondern auch die beschränkte menschliche Wahrnehmung ex negativo zur Einsicht einer höheren Schönheit als die äußerlich erfahrbare „hinaufgeführt“ werden (anagogisch bedeutet so viel wie „nach oben führend“). Schönheit und Hässlichkeit sind in diesem Argument gleichermaßen adäquater Ausdruck der Engel, ja, sie sind beide nötig, um unzulässige Identifikationen mit ihren äußeren Erscheinungsformen

143 Pseudo-Dionysius Areopagita, Himmlische Hierarchie, Kapitel 2, § 3. 
zu verhindern. So wird die anthropomorphisierte idealschöne Figuration des Engels durch eine Projektierung auf das Unmenschliche austariert, das seltsam und bedrohlich in die menschliche Lebenswelt einbricht und in dem bekannten Ausspruch „Fürchtet euch nicht“ (etwa Lk 2,10) der Engel zum Ausdruck kommt.

Der Religionswissenschaftler Rudolf Otto fasst Anfang des 20. Jahrhunderts in seiner Phänomenologie des Heiligen diesen „Doppelcharakter des Numinosen" ${ }^{144}$ in der Formel des mysterium tremendum et fascinans. Deren Wirkung parallelisiert er mit der ästhetischen Erfahrung und vergleicht sie mit dem Erlebnis des Erhabenen, zu dem eine „verborgene Verwandtschaft“"145 bestehe. Zugleich streicht er die enge Verbindung zwischen dem Mysteriösen und den Engeln und Dämonen heraus: „Das Mysteriöse lebt und webt hier [in der semitischen Religion, L.Z.] stark in den Vorstellungen des Dämonischen und Engelischen, von dem diese Welt als von dem ,Ganz andern' umgeben, überhöht und durchdrungen ist." ${ }^{146}$ Der Engel ist also eine Art ideographisches Zeichen des Numinosen, das sowohl das unermesslich Schöne als auch das unfassbar Schreckliche in sich begreift. Er verkörpert damit nicht nur die ästhetische Erfahrung, sondern auch die Erfahrung des Erhabenen, und zwar sowohl in seiner überwältigungsästhetischen Erscheinung als auch auf einer strukturellen Ebene. So besteht eine grundsätzliche Analogie zwischen dem Engel als imaginationsbildender Figur der Darstellung des Undarstellbaren (des göttlichen Mysteriums) und dem Erhabenen, ${ }^{147}$ über das die unaufhebbare Kluft von Idee und Wirklichkeit beziehungsweise hier von Spiritualität und sinnlicher Wahrnehmung erfahrbar wird. Über seine paradoxe (Anti-)Ästhetik ist der Engel das Medium einer Grenzerfahrung und ermöglicht damit die größtmögliche Näherung an Gottes Unverfügbarkeit.

144 Rudolf Otto, Das Heilige. Über das Irrationale in der Idee des Göttlichen und sein Verhältnis zum Rationalen, Breslau 1917, S. 39.

145 Otto, Das Heilige, S. 78. Vgl. dazu Wolfgang Braungart: „In der Gestaltung und der Erfahrung des Schönen und des Erhabenen konvergieren ästhetische und religiöse Momente“ (Wolfgang Braungart, Ästhetische Religiosität oder religiöse Ästhetik? Einführende Überlegungen zu Hofmannsthal, Rilke und George und zu Rudolf Ottos Ästhetik des Heiligen. In: Ästhetische und religiöse Erfahrungen der Jahrhundertwenden, Bd. 2, hg. von Wolfgang Braungart, Gotthard Fuchs u. Manfred Koch, Paderborn u. a. 1998, S. 15-29, hier S. 20). Vgl. dazu auch folgenden Passus in der Kritik der Urteilskraft: „Das Gemüt fühlt sich in der Vorstellung des Erhabenen in der Natur bewegt: da es in dem ästhetischen Urteile über das Schöne derselben in ruhiger Kontemplation ist. Diese Bewegung kann (vornehmlich in ihrem Anfange) mit einer Erschütterung verglichen werden, d. i. mit einem schnellwechselnden Abstoßen und Anziehen eben desselben Objekts“ (Kant, Kritik der Urteilskraft, S. 592).

146 Otto, Das Heilige, S. 88.

147 Vgl. Jörg Heininger, Erhaben. In: Ästhetische Grundbegriffe, Bd. 2, hg. von Karlheinz Barck, Martin Fontius, Dieter Schlenstedt, Burkhart Steinwachs u. Friedrich Wolfzettel, Stuttgart; Weimar 2010, S. 275-310, hier S. 276-277. 
Die genuine Unähnlichkeit der Engel mit sich selbst ist eine der vielen angelischen Unstimmigkeiten, die hier epistemologische beziehungsweise axiologische Implikationen hat. So weisen die markierte Widersprüchlichkeit und Pluralität ihrer Erscheinungsformen die Engel zunächst als Träger einer negativen Ästhetik aus, in Reaktion auf einen unerreichbar entrückten Gott, von dem sich trotz seiner Ferne etwas mitteilen lassen soll. Gleichzeitig rückt sie ihre ästhetische Vielfalt aber auch in die Nähe des Bösen. Denn vielfältige Erscheinungsweisen und eine überbordende Ästhetik sind genuine Bestandteile satanischer Figurationen. Ein ästhetisches Täuschungsprogramm gehört zum Repertoire des Teufels, der sich über seine Erscheinung nicht zweifelsfrei identifizieren lässt und sich sogar mit Vorliebe als Engel ausgibt: „[...] denn er selbst, der Satan, verstellt sich als Engel des Lichts.“ (2 Kor 11,14) ${ }^{148}$ Indem der Engel mit seinen strahlenden wie monströsen Erscheinungsformen über sein Äußeres ebenso wenig verlässlich zugeordnet werden kann, ist er dem Teufel als demjenigen, der „durcheinanderwirft“ ( $\delta \iota \alpha \beta \alpha \dot{\lambda} \lambda$ $\lambda \varepsilon เ v)$, sehr nah: Wie der Teufel fordert dieser Logik nach auch der Engel in der Nicht-Identität von Wesen und Erscheinung nicht nur das Gute, sondern auch jene Ordnung selbst heraus, die der Bestimmung von Gutem und Bösem zugrunde liegt.

Engel sind aber nicht nur Ausdruck einer prononcierten Ästhetik, sondern auch selbst wiederum Produzenten von Bildern und Figuren, indem sie laut Thomas von Aquin unmittelbar auf die Einbildungskraft einwirken und beispielsweise Joseph im Schlaf erscheinen (vgl. Mt 1 u. 2). Dieses Wirken ist unabdingbar für die Erkenntnisvermittlung, denn „[d]ie menschliche Vernunft [...] kann nicht das vernünftig Erkennbare erfassen, wenn dieses nackt und rein in seiner Vernünftigkeit vorgelegt wird; denn es ist ihrer Natur angemessen, nur dadurch zu erkennen, daß sie sich zu den Phantasiebildern wenden“149. Aus diesem Grund „legen die Engel die erkennbare Wahrheit unter Figuren und Bildern vor, die von sichtbaren Dingen hergenommen sind“150. Die Engel eröffnen in ihrer Vermittlung zwischen mundus sensibilis und mundus intelligibilis den Raum des mundus

148 Darüber hinaus nutzt der Teufel das Aisthetische, also das sinnlich Wahrnehmbare, mit Vorliebe als Vehikel seiner Machenschaften, etwa wenn er den Heiligen Antonius mit opulenten Bildern vom Pfad der Tugend abzubringen sucht. Und auch der gefallene Engel scheint von besonderer Schönheit zu sein: „Durch deinen großen Handel wurdest du voll von Gewalttat und hast dich versündigt. Da verstieß ich dich vom Berge Gottes und tilgte dich, du schirmender Cherub, hinweg aus der Mitte der feurigen Steine. Weil sich dein Herz erhob, dass du so schön warst, und du deine Weisheit verdorben hast in all deinem Glanz, darum habe ich dich zu Boden gestürzt und ein Schauspiel aus dir gemacht vor den Königen.“ (Hes 28,16-17) Vgl. auch „Wie bist du vom Himmel gefallen, du schöner Morgenstern!“ (Jes 14,12).

149 Thomas von Aquin, Summe der Theologie, Prima Pars, Quaestio 111, Artikel 1b.

150 Thomas von Aquin, Summe der Theologie, Prima Pars, Quaestio 111, Artikel 1b. 
imaginalis. Sie sind damit Medien der Einbildungskraft. ${ }^{151}$ So ist die Phantasie, die ästhetischen Überfluss produziert und bei Enthaltsamkeit den Asketen mit besonders verführerischen Bildern quält, eng mit den Engeln verbunden. Und es besteht die Gefahr, dass Bilder ohne jeden Bezug zur Vernunft erscheinen. Da gute Engel keine Täuschungsabsicht haben können, macht Thomas den Grund dafür in Defiziten der menschlichen Vernunft aus. ${ }^{152}$ Allerdings muss er einräumen, dass diese Einwirkung auch durch böse Engel geschehen kann, ohne dass er Kriterien zur Unterscheidung an die Hand gibt. Die Phantasie bleibt damit ambivalent, da sie einerseits Wahrheit offenbaren, diese andererseits aber auch nur vortäuschen und Menschen so vorsätzlich verwirren kann.

Die Ambivalenz der Engel, die darin liegt, dass sich nicht zweifelsfrei entscheiden lässt, ob die mit ihnen verbundene Imagination im Dienst der richtigen Sache steht, zeigt auch die doppelte Perspektive in der Bibel an. So bleibt beispielsweise die Information, dass es sich um „zwei Engel“ (1 Mos 19,1) handelt, die zu Lot kommen und ihn vor der Zerstörung der Stadt Sodom aus ihr herausführen, Leserinnen und Lesern vorbehalten; den Protagonisten erscheinen sie nur als „Männer“ (1 Mos 19,5). Der Engel ist damit ein potentiell „böses Medium“"153, das unter latentem Täuschungsverdacht steht. Die Frage des Bösen ist eine, die immer mitschwingt - zumal in der Moderne. Denn die Komplizenschaft von Bösem und Ästhetischem kann sich erst dann voll entfalten, wenn die Kunst im 18. Jahrhundert mit dem Programm der sogenannten Autonomieästhetik aus dem Korsett moralischer Heteronomie befreit wird, ${ }^{154}$ und so das Böse ebenso

151 Auch die Phantasie ist damit ein Einfallstor für Widergöttliches. In dem Sichtbarmachen von Unsichtbarem ebenso wie als Lenker der Phantasie sind Engel ästhetische Figuren der Imagination, über die sich göttliche Vollkommenheit schleichend zu künstlerischer Meisterschaft wandelt: „Vollkommenheit ist anfänglich ein Prädikat, das in jüdisch-christlicher Tradition Gott allein zukommt und das gleichermaßen zum Glücksprivileg antiker Götter gehört. Da die göttliche Vollkommenheit indes nicht ohne Imagination vorstellbar und erfahrbar werden kann, fand die ästhetische Erfahrung im Medium des Imaginären den Ansatzpunkt, sich fortschreitend der Gestalten und Sinnstrukturen des Vollkommen zu bemächtigen und schließlich die Aura göttlicher Vollkommenheit für die Kunst als höchstes Menschenwerk zu beanspruchen“ (Jauß, Ästhetische Erfahrung und literarische Hermeneutik, S. 305).

152 Vgl. Thomas von Aquin, Summe der Theologie, Prima Pars, Quaestio 111, Artikel 3c.

$153 \mathrm{Zu}$ „bösen Medien“ vgl. Markus Krajewski u. Harun Maye, Was sind böse Bücher? In: Böse Bücher. Inkohärente Texte von der Renaissance bis zur Gegenwart, hg. von Markus Krajewski u. Harun Maye, Berlin 2019, S. 7-27, hier S. 10.

154 Konstitutiv für das von den Zwängen des Nützlichkeitspostulats befreite Schöne galt Karl Philipp Moritz, dass es „keines Endzwecks, keiner Absicht warum es da ist, außer sich bedarf, sondern seinen ganzen Wert und den Endzweck seines Daseins in sich selber hat" (Karl Philipp Moritz, Über die bildende Nachahmung des Schönen. In: Moritz, Werke in zwei Bänden, Bd. 1, ausgewählt und eingeleitet von Jürgen Jahn, Berlin; Weimar 1973, S. 255-290, hier 
wie der Engel, der als gefallener eine Figuration der Autonomie durch den Gebrauch des freien Willens darstellt, in gesteigertem Maße Figuren der ästhetischen Selbstreflexion werden. Gleichzeitig bleibt das Böse auf jene Spannung aus Verbot und Überschreitung angewiesen, die von der Religion auf die Literatur übergeht und deren „,böse Ausrichtung“155 begründet.

Die Gefahr der Täuschung beziehungsweise Fälschung betrifft nicht nur die Erscheinung der Engel, sondern auch den performativen Akt ihrer Botschaftsübermittlung. Hier wird der Engel zum konsubstantiellen Stellvertreter Gottes, der ihn nicht nur symbolisiert, sondern seine Präsenz auch verwirklicht. So heißt es in 1 Mos 22,11-12, als Abraham seinen Sohn opfern soll:

Da rief ihn der Engel des HERRN vom Himmel und sprach: Abraham! Abraham! Er antwortete: Hier bin ich. Er sprach: Lege deine Hand nicht an den Knaben und tu ihm nichts; denn nun weiß ich, daß du Gott fürchtest und hast deines einzigen Sohnes nicht verschont um meinetwillen [meine Hervorhebungen, L.Z.].

In der Engelserscheinung fallen Zeichen und Bezeichnetes momenthaft zusammen. In der Folge ist nicht mehr klar, ob es Gott oder der Engel ist, der spricht und handelt - „[d]er Text der Bibel schwankt gleichsam wie ein Blinklicht zwischen der Stimme Gottes und der Stimme des Engels“156, wie Michel Serres feststellt. In der Geschichte von Manoach und seiner Frau, denen der Engel des Herrn die Geburt eines Sohns prophezeit, geht die Überschneidung so weit, dass die Beteiligten die Erscheinung des Engels mit der Gottes gleichsetzen:

Und als die Flamme aufloderte vom Altar gen Himmel, fuhr der Engel des HERRN auf in der Flamme des Altars. Als das Manoach und seine Frau sahen, fielen sie zur Erde auf ihr Angesicht. Und der Engel des HERRN erschien Manoach und seiner Frau nicht mehr. Da erkannte Manoach, dass es der Engel des HERRN war, und sprach zu seiner Frau: Wir müssen des Todes sterben, weil wir Gott gesehen haben.

(Ri 13,20-22)

In den dialogischen Ausführungen in Michel Serres' Die Legende der Engel werden diese Überblendungen als konstitutiv für Kommunikationsprozesse überhaupt verstanden: „Die Bibel bringt in diesen Texten das Grundproblem der

S. 262). Die postulierte Autonomie ist allerdings keine unbedingte; so setzt Karl Philipp Moritz der Vorstellung eines schrankenlosen Schönen im Bereich des Handelns Grenzen: „Durch den Mittelbegriff des Edeln also wird der Begriff des Schönen wieder zum Moralischen hinübergezogen und gleichsam daran festgekettet. Wenigstens werden dem Schönen dadurch die Grenzen vorgeschrieben, die es nicht überschreiten darf“ (Moritz, Über die bildende Nachahmung des Schönen, S. 260).

155 Gerd Bergfleth, Die Souveränität des Bösen. Zu Batailles Umwertung der Moral. In: Georges Bataille, Die Literatur und das Böse, München 1987, S. 189-236, hier S. 193.

156 Serres, Die Legende der Engel, S. 106. 
Kommunikation zum Ausdruck. “157 Der Engel fungiert daher in Serres’ Werk als Sinnbild universaler Übersetzungsprozesse, die die Welt konstituieren, sowie einer weltumspannenden Verschaltung, da er - analog zu neuen Medien - heterogene Bereiche verknüpft. ${ }^{158}$ Das fast durchgehend dialogisch aufgebaute Werk, das überwiegend aus Gesprächen der Flughafenärztin Pia, dem Inspizienten der Air France, Pantope, und Pias Bruder Jacques besteht, ist selbst wesentlich angelisch konzipiert: Bedeutung geht nicht klar aus der Aussage eines Sprechers oder einer Sprecherin hervor, sondern entsteht aus dem Wechselspiel des Dialogs und dem ambiguen Spannungsfeld von Intention und medialer Übertragung, die die genaue Zuordnung der Aussagen verunklart. Damit stellt das Werk selbst die Zwiespältigkeit angelisch vermittelter Kommunikation aus. Funktionale und ethische Dimension der Kommunikation sind hier untrennbar verknüpft, die Gefahr, dass der Engel als prototypisches Medium nicht hinter der Botschaft zurücktritt, sondern sich diese in ihrer Vermittlung aneignet und somit verfälscht, ist immer virulent. ${ }^{159}$ Diese Bedrohung ist der Tätigkeit des Engels notwendig eingeschrieben: Er muss erscheinen, um seine Botschaft zu übermitteln, aber er muss ebenso verschwinden und hinter seiner Aussage zurücktreten, da es nie um ihn geht.

Im Bereich der Kunst potenzieren sich angelische Unstimmigkeiten und metaästhetische Reflexionen, denn man hat es bei der Darstellung von Engeln mit der Darstellung der Darstellung zu tun. Die Aisthetisierung von Unsinnlichem erweitert sich in den Zeichensystemen der Sprache und noch mehr in der bedeutungsamplifizierenden Literatur, ${ }^{160}$ der bildenden Kunst (als „Bilder

157 Serres, Die Legende der Engel, S. 107.

$158 \mathrm{Vgl}$. Serres, Die Legende der Engel, S. 67. Die Verbindung von Engeln und modernen Medien lässt sich mit Agamben um den Aspekt der Herrlichkeit erweitern (die Verherrlichung Gottes ist ein wesentlicher Bestandteil der angelischen Pflichten): „Die heutige Demokratie ist eine Demokratie, die gänzlich auf der Herrlichkeit begründet ist, das heißt auf der durch die Medien vervielfachten und verbreiteten, jede Vorstellung übersteigenden Wirkmacht der Akklamation“ (Agamben, Herrschaft und Herrlichkeit, S. 305). Wie Serres sieht auch Agamben hierin eine Manipulation der Botschaft am Werk: „Und wie es von jeher mit profanen und kirchlichen Liturgien geschieht, wird auch dieses vermeintlich ,ursprüngliche demokratische Phänomen' von den Strategien der spektakulären Macht eingefangen, ausgerichtet und manipuliert“ (Agamben, Herrschaft und Herrlichkeit, S. 305).

159 Mit der Frage, wie dieser Gefahr begegnet werden kann, beschäftigt sich Michel Serres: „Wie kann man sich vor Verrat und Parasitentum, vor Täuschung durch Behinderung der Kommunikation schützen? Aus dieser Frage ergibt sich eine ganze Deontologie der Boten: Wie schafft man es, die übermittelte Sache nicht zu stehlen?“ (Serres, Die Legende der Engel, S. 101).

160 Zur Aisthetisierung vgl. Sybille Krämer, Was haben ,Performativität‘ und ,Medialität‘ miteinander zu tun? Plädoyer für eine in der ,Aisthetisierung‘ gründende Konzeption des Perfor- 
des Bildes“161) oder der Musik (in der die Spannung von göttlicher Abstraktion und angelischer Konkretion in einem ungegenständlichen Medium verhandelt wird), ${ }^{162}$ sodass Engelsdarstellungen immer schon auf zwei Ebenen operieren. Die damit verbundene poetologische Dimension lässt sich zum einen im Inspirationstopos finden, das auf eben jenes sinnstiftende Differenzmoment rekurriert wie im Bild des poeta vates, dem die Vorstellung zugrunde liegt, der Künstler habe Zugang zu einer sakralen Sphäre, deren Widerschein er in der poietischen Verwandlung materialisiert. Zum anderen lässt sich auch wissensgeschichtlich mit Sigrid Weigel fragen, inwiefern die Kunst in Verweltlichungsprozessen „zum Medium der Verhandlungen zwischen Theologie und Wissenschaft "163 avanciert und damit die strukturell angelische Rolle eines auch wesentlich metaphorisch vermittelten Austauschs einnimmt. Konkret geht es an dieser Stelle in Sigrid Weigels Aufsatz „Die Vermessung der Engel“ (2007) um barocke Maler, welche die Einsicht des kopernikanischen Weltbilds umsetzten, um „das christliche Weltbild als Bild darzustellen“164, also um die durch die Selbstreflexion des kopernikanischen Weltbilds hervorgebrachte Tendenz zur Darstellung der Darstellung. Gleichzeitig zeigen sich die Engel in ihrer anhaltenden Präsenz im 19. Jahrhundert als Scharnierstelle einer disziplinübergreifenden Ausweitung von Wissen, die sowohl den Engeln als auch der Kunst aus ihrer Verortung im Grenzbereich von Empirie und Transzendenz erwächst.

In der Schwellenfigur des transdisziplinären Engels verdichtet sich so „das spekulative Begehren zur Entgrenzung des positiven Wissens auf seinem Weg in den Kosmos“165, womit nicht nur epistemologische, sondern auch poetologische Fragen berührt werden. Ähnlich der Metapher figuriert der Engel den Berührungspunkt verschiedener semantischer Bereiche, markiert also poetologisch einerseits die Grenze und Differenz, und impliziert andererseits immer auch die Schwelle als Möglichkeit der Berührung und überschreitenden Vermischung. ${ }^{166}$ In ihrer Affini-

mativen. Zur Einführung in diesen Band. In: Performativität und Medialität, hg. von Sybille Krämer, München 2004, S. 13-32.

161 Weigel, Die Vermessung der Engel, S. 254.

162 In der Zeit der Kirchenväter wurde der angelische Schöpfungsjubel mit der Lehre der Sphärenharmonie zusammengeführt und bei Boethius um die Verknüpfung mit einer musikalischen Harmonie erweitert, die dem Jubel der Engel akustisch Ausdruck verlieh (vgl. Herkommer, Sphärenklang und Höllenlärm, Lächeln oder Fratzen, S. 206-207).

163 Weigel, Die Vermessung der Engel, S. 249.

164 Weigel, Die Vermessung der Engel, S. 249.

165 Weigel, Die Vermessung der Engel, S. 247.

166 Zur Produktivität der Grenze vgl. Jurij Lotman: „Die Brennpunkte der semiotisierenden [semioobrazovatel'nye] Prozesse befinden sich aber an den Grenzen der Semiosphäre. Der Begriff der Grenze ist ambivalent: Einerseits trennt sie, andererseits verbindet sie. Eine Grenze 
tät zur Metapher als einem vertikalen Übertragungsvorgang stehen Engel für die Berührung von gestaltlosen Signifikanten und der Materialität ikonischer Darstellung. Hier lässt sich auch der Bogen zu Mary Douglas' Ordnungskonzept schlagen, in dem Unordnung nicht nur Gefahr, sondern auch schöpferisches Potential signalisiert. ${ }^{167}$ Innerhalb eines theozentrischen Weltbilds wird solches als Bedrohung verstanden. Diese Bewertung erfährt mit dem Bruch der theozentrischen Ordnung in der Moderne eine entscheidende Wandlung.

Viele der Fragen, deren zufriedenstellende Beantwortung für die vormodernen Angelologien von entscheidender Bedeutung waren, haben ihre Virulenz im 20. Jahrhundert verloren, in dem völlig andere Rahmenbedingungen gelten. Die Natur der angelologischen Verbindungslinien ist daher struktureller und figurativer Art. Entsprechend geht es in dieser Studie nicht darum, eine moderne Fortschreibung spätantiker Angelologien in literarischen Werken auszumachen; vielmehr adaptieren diese die ambivalenten Bilder und paradoxen Strukturen, die in einem Bezug zu der spezifischen Situation ihrer Verfasserinnen und Verfasser stehen. Dazu gehören insbesondere die Debatten um umfassende Verlusterfahrungen: Verlust an Ordnung im Zuge der beiden Weltkriege, an Menschlichkeit durch die Dehumanisierung im Nationalsozialismus, an Verwurzelung im Exil des modernen Menschen, an Anschaulichkeit durch technische Entwicklungen und schließlich die Erfahrung des Verlusts von Erfahrung selbst.

\subsection{Der Engel als Reflexionsfigur moderner Debatten}

Die Untersuchung von Engelsfiguren in Texten des 20. Jahrhunderts ruft mit Religion und Moderne zwei Diskursfelder auf, die inkompatibel erscheinen und zugleich untrennbar miteinander verbunden sind. ${ }^{168}$ Diese Spannung reflektiert der

grenzt immer an etwas und gehört folglich gleichzeitig zu beiden benachbarten Kulturen, zu beiden aneinandergrenzenden Semiosphären. Die Grenze ist immer zwei- oder mehrsprachig“ (Jurij M. Lotman, Die Innenwelt des Denkens. Eine semiotische Theorie der Kultur, Berlin 2010, S. 182).

167 Vgl. Douglas, Reinheit und Gefährdung, S. 124.

168 Nach Suzanne Hobson, die die vielfältigen Figurationen von Engeln in der angloamerikanischen modernen Literatur untersucht, finden sich zwei gegenläufige Stoßrichtungen: Einerseits stellten die Engel eine Bastion gegen Säkularisierungstendenzen in Kunst und Religion dar, andererseits seien sie in ihrer Indienstnahme für eine Vielzahl emanzipatorischer Bewegungen genuin säkulare Figuren, wobei sich diese Interessen ,from sex-reform campaigners to designers of new utopias“ erstreckten (Hobson, Angels of Modernism, S. 1). Suzanne Hobson plädiert in der Frage nach Umfang und Reichweite der Säkularisierung im 20. Jahrhundert für eine differen- 
Engel, indem er einerseits Repräsentant einer religiösen Ordnung ist, andererseits aber als weltliche Fliehkraft wirkt, die aus der Geschlossenheit der numinosen Sphäre herausdrängt. Indem er deren Botschaften und Strukturen in die Welt trägt, lässt er sich als Vehikel einer oft als Säkularisierung bezeichneten Transformation verstehen. Meist wird unter diesem Begriff vage die Abnahme von Religiosität beziehungsweise die Umkodierung sakraler Gehalte ins Profane im Zuge verschiedenster der Modernisierung zugerechneter Prozesse verstanden. Die Unschärfe der solcherart zusammengebundenen Phänomene ist in der Vieldeutigkeit des Begriffs angelegt. Denn „Säkularisierung“ kann „sowohl ,Schwächung von Religion“ wie auch ,Verwirklichung der Religion““ bedeuten - „und einiges mehr“169, wie Hans Joas schreibt. Ob man derartig bezeichnete Zustandsveränderungen als Verlust oder im Gegenteil als Gebietsgewinn auffasst, hängt wesentlich mit Perspektivierung und argumentativer Stoßrichtung zusammen. ${ }^{170}$ Ursprünglich begrenzt auf das Kirchen- und dann das Staatsrecht wurde der Anwendungsbereich

ziertere Sicht, die ihre Universalität und Unausweichlichkeit bestreitet. Gleichwohl will sie die Säkularisierungsthese als Kontextualisierungsfolie für die moderne Kultur nicht aufgeben. Indem sich in den Engelsfiguren der Moderne sowohl sakrale als auch säkulare Tendenzen bündelten, spiegle sich in ihnen das Ineinander von Säkularisierungs- und Resakralisierungstendenzen um 1900. Es sei „precisely the angel's lack of fit with self-consciously ,modern“ aesthetic and secular interests that explains the figure's continued attraction to modernist writers as well as its capacity to generate new meanings“ (Hobson, Angels of Modernism, S. 1). Aufgrund ihrer schillernden, ambivalenten Beschaffenheit stießen die Engel gerade in der Heterogenität moderner Strömungen auf Begeisterung und würden als kardinale Figuren für eine große Bandbreite an gesellschaftspolitischen Zielsetzungen reklamiert (vgl. Hobson, Angels of Modernism, S. 10-11).

169 Hans Joas, Im Bannkreis der Freiheit. Religionstheorie nach Hegel und Nietzsche, Berlin 2020, S. 160. Hans Joas selbst hat sieben Bedeutungen des Begriffs unterschieden. Zwei Bedeutungen seien rechtlicher Natur („Übergang eines Ordenspriesters ins Weltpriestertum; Enteignung von Kirchenbesitz“); zwei beträfen das - affirmative oder kritische - Verhältnis von moderner Kultur und religiöser abendländischer Tradition; drei der Bedeutungen seien in den Sozialwissenscchaften verbreitet („Abnahme von Religion; Rückzug der Religion ins Private; Freigabe gesellschaftlicher Bereiche von religiöser Kontrolle“). Und schließlich habe Charles Taylor in A Secular Age eine achte Bedeutung herausgearbeitet, nämlich die Entstehung einer Wahlmöglichkeit mit der Option des Unglaubens (Joas, Im Bannkreis der Freiheit, S. 250-251). 170 Das betrifft auch den Begründer der Gott-ist-tot-Diagnose, Friedrich Nietzsche. So hat Vietta anschaulich auf die Zweideutigkeit von Nietzsches Theologiekritik und der religiös verwandten Sprachweise hingewiesen: In seiner Zertrümmerung des alten christlichen Gottes übernehme Nietzsche nicht nur „Sprechformen, die der christlichen Frömmigkeit zutiefst verbunden bleiben, sondern geradezu die Leidenshaltung des christlichen Gottes selbst. In dem Maße, wie er jenen zertrümmert, verwächst Nietzsche immer mehr mit der christlichen Erlösungshaltung“ (Silvio Vietta, Zweideutigkeit der Moderne: Nietzsches Kulturkritik, Expressionismus und literarische Moderne. In: Die Modernität des Expressionismus, hg. von Thomas Anz u. Michael Stark, Stuttgart; Weimar 1994, S. 9-20, hier S. 12). 
des Säkularisierungsbegriffs seit Mitte des 19. Jahrhunderts als ein kulturdiagnostisches Instrument erweitert. ${ }^{171}$ Entsprechend herrscht hinsichtlich der konkreten Datierung keinerlei Einigkeit, ${ }^{172}$ was vor allem daran liegt, dass die Reichweite des Begriffs als „kulturgeschichtlich[e] Metapher“"173 ausgedehnt und machtpolitisch aufgeladen wurde, etwa für die Abgrenzung einer ,zivilisierten` Sphäre gegenüber dem vermeintlich rückständigen Rest der Welt. ${ }^{174}$ Gleichzeitig haben Profanisierungsprozesse ihre historischen wie systematischen Wurzeln in den religiösen Ordnungen selbst. Insbesondere das missionierende Christentum, das andere Religionen als Aberglauben denunzierte und teils brutal gegen sogenannte Häretikerinnen und Häretiker in den eigenen Reihen vorging, bereitete einer Entzauberung des gläubigen Blicks den Weg. Wie alle monotheistischen Religionen, die auf einem propagierten Gefälle zwischen richtigem Gott und falschen Göttern basieren, trägt auch das Christentum eine fundamentale Religionskritik in sich. ${ }^{175}$ Diese Tendenz verschärfte sich im Protestantismus des 19. Jahrhunderts, als es vor allem ,protestantische ,Dissidenten““176 waren, die zu einer Verweltlichung religiöser Strukturen beitrugen. ${ }^{177}$ Auf der Ebene religiöser Praxis wiederum bedeutet die Versinnlichung unsinnlicher Glaubensgehalte eine für jede Religion medienästhetische Notwendigkeit, sodass „Säkularisierung [...] ein

171 Vgl. Ulrich Ruh, Bleibende Ambivalenz. Säkularisierung/Säkularisation als geistesgeschichtliche Interpretationskategorie. In: Ästhetik - Religion - Säkularisierung I. Von der Renaissance zur Romantik, hg. von Silvio Vietta u. Herbert Uerlings, München 2008, S. 25-36, hier S. 25.

172 So befinden etwa Silvio Vietta und Herbert Uerlings: „Der Prozess der Säkularisierung beginnt viel früher, als es insbesondere die germanistische Forschung lange Zeit annahm. Er beginnt bereits im Mittelalter bzw. in der Frührenaissance und erlebt - im Anschluss daran - in der Romantik einen neuen Höhepunkt“ (Silvio Vietta u. Herbert Uerlings, Einleitung: Ästhetik Religion - Säkularisierung. In: Ästhetik - Religion - Säkularisierung I. Von der Renaissance zur Romantik, hg. von Silvio Vietta u. Herbert Uerlings, München 2008, S. 7-23, hier S. 10).

173 Dirk Kemper, Literatur und Religion. Von Vergil bis Dante. In: Ästhetik - Religion - Säkularisierung I. Von der Renaissance zur Romantik, hg. von Silvio Vietta u. Herbert Uerlings, München 2008, S. 37-53, hier S. 43.

174 Vgl. Koschorke, ,Säkularisierung‘ und ,Wiederkehr der Religion', S. 240-243.

175 Vgl. Koschorke, ,Säkularisierung‘ und ,Wiederkehr der Religion', S. 250. Vgl. auch Suzanne Hobson: „In fact, secularity finds its origins in religion; there is an ,epic irony“ in the fact that secularism is the outcome of successive drives to purify religion, to get rid of folk beliefs, for example, or turn a ,higher religion' available only to an élite into a more democratic faith based on personal communication with God“ (Hobson, Angels of Modernism, S. 6).

176 Koschorke, ,Säkularisierung‘ und ,Wiederkehr der Religion‘, S. 250.

177 Vgl. zur Entstehung der Säkularisierungstheorie Manuel Borutta, Genealogie der Säkularisierungstheorie. Zur Historisierung einer großen Erzählung der Moderne. In: Geschichte und Gesellschaft, 36, 2010, S. 347-376. 
beinahe zwangsläufiger Prozess der im religiösen Ritual fundierten menschlichen Kultur zu sein" ${ }^{178}$ scheint.

Angesichts dieser begrifflichen Universalisierung der Säkularisierung und befeuert von der Auflösung europäischer Deutungsmacht wuchsen die Zweifel an jenen schematischen Modernetheorien, ${ }^{179}$ die von einer zwangsläufigen Entwicklung hin zu einer religionsfreien modernen Aufgeklärtheit ausgehen. Zwar schließen neuere Bestimmungsversuche strukturell häufig an die Säkularisierung als Meistererzählung an, indem sie je nach Perspektive mit dem Schema eines ImmerNoch, Nicht-Mehr, Überhaupt-Nicht, Noch-Nicht oder Beides-Zugleich derselben Logik verhaftet sind (sei es Peter Bergers Diagnose einer „Desäkularisierung“180 oder Habermas’ Befund einer „postsäkularen Gesellschaft“181). Gleichzeitig verunsichert aber der Blick auf solche zeitlichen Strudel die Linearität des gesamten Diskurses und stellt ihn unter das Vorzeichen des Unheimlichen, des Schwankens zwischen Präsenz und Absenz. Aufgeschobener Tod, Untotsein oder unerwartete Wiedergeburt werden hier je nach Perspektive den universal ausgerichteten Modernisierungstheorien nach 1945 oder der unter chronischem Anachronismusverdacht stehenden Religion attestiert. So schreibt Jonathan Sheehan zu Beginn seiner Studie The Enlightenment Bible von 2005: „Prophets of modernity count the hours until religion's death. They should not hold their breath."182 Daniel Weidner befindet, wir stünden einer „renaissance of religion in Europe“ gegenüber, „a notion that may sound strange in the United States, where religion never disappeared“"183. Umgekehrt heißt es in der Einleitung zu dem Band Moderne und Religion von 2013: „Die längst totgesagte Modernisierungstheorie aus der Mitte des 20. Jahrhunderts ist unbestreitbar der heimliche oder offen angesprochene Referenzpunkt der gegenwärtigen Kontroversen um die Moderne.“"184

178 Vietta u. Uerlings, Einleitung, S. 11. Gleich darauf relativieren sie allerdings: „Ob Säkularisierung tatsächlich ein im angedeuteten Sinne ,zwangsläufiger‘ Prozess ist, steht freilich dahin“ (Vietta u. Uerlings, Einleitung, S. 11).

179 Vgl. Koschorke, ,Säkularisierung، und,Wiederkehr der Religion‘, S. 237-239.

180 Peter Berger, The Desecularization of the World: A Global Overview. In: The Desecularization of the World, hg. von Peter Berger, Grand Rapids 1999, S. 1-18.

181 Vgl. Jürgen Habermas, Glauben und Wissen. Friedenspreisrede 2001. In: Habermas, Zeitdiagnosen. Zwölf Essays 1980-2001, Frankfurt am Main 2003, S. 249-262.

182 Jonathan Sheehan, The Enlightenment Bible. Translation, Scholarship, Culture, Princeton 2005, S. IX.

183 Daniel Weidner, Thinking Beyond Secularization: Walter Benjamin, the „Religious Turn“, and the Poetics of Theory. In: New German Critique, 111, 2010, S. 131-148, hier S. 147.

184 Detlef Pollack, Ulrike Spohn u. Thomas Gutmann, Einleitung. In: Moderne und Religion. Kontroversen um Modernität und Säkularisierung, hg. von Detlef Pollack, Ulrike Spohn u. Thomas Gutmann, Bielefeld 2013, S. 9-23, hier S. 9. 
Der Religion kommt in diesem Verhältnis üblicherweise die Rolle eines Störfaktors $\mathrm{zu}$, der so tief mit der modernen Konstitutionsgeschichte verbunden ist, dass er nur verdrängt, nicht aber völlig eliminiert werden kann. ${ }^{185}$ Mit der Anerkennung einer definitorischen Verschränkung wird umgekehrt auch der Status der Modernisierungstheorien ein unheimlicher. Nach Albrecht Koschorke führen sie mitsamt dem Säkularisierungstheorem eine geisterhafte Existenz und irrten, ihrer Fundierung im europäisch-kolonialistischen Fortschrittsdenken beraubt, „gewissermaßen heimatlos durch die Welt“'186.

Wenn die scharfen Grenzziehungen der narrativen Konstrukte einer vormodernen Religiosität und eines modernen Atheismus sich bei näherem Hinsehen als derart unzuverlässig erweisen, ${ }^{187}$ kommt den Überschneidungen zwischen

185 Vgl. Sheehan, The Enlightenment Bible, S. IX. Vgl. dazu auch Christof Dipper: „Herkömmlicherweise verstehen sich Religion und Moderne als Antipoden, hat doch nach gegenwärtiger Mehrheitsmeinung die Moderne ihren Ursprung in der Religionskritik der Aufklärung. Aber eben dadurch sind beide seit jeher auch aufeinander verwiesen“ (Christof Dipper, Religion in modernen Zeiten. Die Perspektive des Historikers. In: Moderne und Religion. Kontroversen um Modernität und Säkularisierung, hg. von Ulrich Willems, Detlef Pollack u. Helene Basu, Bielefeld 2013, S. 261-292, hier S. 268). Treml und Weidner reflektieren die Präsenz von Religion in der Moderne als eine unheimliche: „Unser Vorschlag ist es, Religion weder mit dem Modell des Verschwindens, noch mit dem der Wiederkehr, sondern mit dem des Nachlebens zu beschreiben. Vielleicht kann dieser Begriff in seiner unheimlichen Struktur die eigenartige Präsenz der Religion, zumal in der Moderne, besonders gut treffen. Denn Nachleben schwankt zwischen Überleben und Hinterlassen, es ist weder ungebrochenes Fortleben, noch auch ein klar bestimmter Abbruch“ (Martin Treml u. Daniel Weidner, Zur Aktualität der Religionen. Einleitung. In: Nachleben der Religionen. Kulturwissenschaftliche Untersuchungen zur Dialektik der Säkularisierung, hg. von Martin Treml u. Daniel Weidner, München 2007, S. 7-22, hier S. 11).

186 Koschorke, ,Säkularisierung‘ und ,Wiederkehr der Religion‘, S. 238.

187 Die Frage, wie es sich mit der empirischen Grundlage der jeweiligen Thesen verhält, ist hochgradig umstritten. Albrecht Koschorke kommt zu dem Schluss, dass „[a]m Ende [...] nicht einmal die These vom säkularen Europa Bestand“ hat (Koschorke, ,Säkularisierung“ und ,Wiederkehr der Religion', S. 237-238). Allerdings bestreitet er grundsätzlich, dass die Entstehung des Säkularisierungsnarrativs (ebenso wie sein Niedergang) eine Grundlage in empirischen Gegebenheiten hätte - zumindest sofern diese so etwas wie eine religiöse Substanz beziehungsweise deren Schwinden betreffen. Entscheidend sind für ihn vielmehr die Machtverhältnisse und ihre Objektivationen, die eine Einheitssemantik wie die Säkularisierungsthese in ihrer Resistenz gegen Kontraevidenzen stärkten bzw. dies in ihrem Niedergang nicht mehr ausreichend könnten (vgl. Koschorke, ,Säkularisierung، und ,Wiederkehr der Religion‘, S. 238). Hinzu kommen Konstruktionszwänge, die aus dem Narrativ selbst resultierten und die umgekehrt auch auf institutioneller Ebene ihre Wirkmacht entfalteten (vgl. Koschorke, ,Säkularisierung‘ und ,Wiederkehr der Religion“, S. 258). Auch Manuel Borutta fragt, „warum Sozialwissenschaftler so lange an die Säkularisierungstheorie geglaubt haben (oder dies immer noch tun): Wie konnte diese Theorie zu einem regelrechten Definiens von Modernität werden?“ (Borutta, Genealogie 
sakraler und profaner Sphäre und damit dem angestammten Bereich der Engel gesteigerte Bedeutung zu. Löst man sich von einer „normativen Säkularisierungserzählung“"188, dann geraten die ästhetischen, politischen und geschichtsphilosophischen Implikationen der religiösen Dimension moderner Angelophanien in den Blick. So können anhand der dynamischen und ständig neu perspektivierten Wechselbeziehungen zwischen sakraler und profaner Sphäre, die der Engel in Texten des 20. Jahrhunderts etabliert, Einsichten in das jeweilige Verständnis von Modernität gewonnen werden. Sowohl die ästhetisch-profane Tendenz als auch der Bezug zu einer heiligen Hierarchie werden dabei für ganz unterschiedliche Aussageabsichten genutzt. Hier verschiebt sich das Provokations- und Innovationspotential der Engelsfigur: War in den spätantiken und scholastischen Angelologien ihre ästhetische und korporale Seite mit Unterbrechung und Antinormativität verbunden, so irritiert im 20. Jahrhundert zunehmend die religiöse Bedeutung der Engel, die innerhalb eines modernen Selbstverständnisses mit einer rückwärtigen Säkularisierungsperspektive als unzeitgemäß erscheint.

Nachdem die angelologischen Kontroversen im Zuge von Reformation und Aufklärung an Bedeutung verlieren, stellt sich zu Beginn des 20. Jahrhunderts angesichts eines Diskurses der spirituellen Entleerung des Kosmos die grundsätzliche Frage, welche Bedeutung Engeln als religiösen Figuren überhaupt noch zukommen soll. ${ }^{189}$ Die von Nietzsches „tollem Menschen“ beschworene „göttliche Verwesung“'190 ist allerorten zu riechen. Gleichzeitig gibt es Anstrengungen, die verlorene Dimension des Absoluten auf neuer Ebene zurückzugewinnen. Siegfried Kracauer beschreibt 1922 das Phänomen einer großen Anzahl von Menschen, die die Haltlosigkeit einer „nicht im Absoluten verankerte[n]

der Säkularisierungstheorie, S. 348). Aus dieser Perspektive scheint nicht die Religion, sondern das Festhalten an der Säkularisierungstheorie der Irrationalität verdächtig. Dagegen wendet Detlef Pollack ein: „Bei der Behauptung, dass Religion und Moderne kompatibel seien, handelt es sich um eine neue Meistererzählung der Sozial- und Geisteswissenschaften, die ihre Faszination vor allem aus der Umkehrung klassischer soziologischer und historischer Annahmen bezieht, in den empirischen Daten jedoch nur eine schwache Abstützung besitzt“ (Detlef Pollack, Religion und Moderne: Theoretische Überlegungen und empirische Beobachtungen. In: Moderne und Religion. Kontroversen um Modernität und Säkularisierung, hg. von Detlef Pollack, Ulrike Spohn u. Thomas Gutmann, Bielefeld 2013, S. 293-329, hier S. 324-325).

188 Polaschegg u. Weidner, Bibel und Literatur, S. 11.

189 Hermann Timm spricht von der „Entgötterung, Entzauberung, Entheiligung und Entmetaphorisierung des Kosmos“ (Hermann Timm, Dichtung des Anfangs. Die religiösen Protofiktionen der Goethezeit, München 1996, S. 18).

190 Nietzsche, Der tolle Mensch, S. 127. 
Seele“191 erkannt und einen positivistischen Weltzugang überwunden habe, dabei aber den Sprung in den Glauben nicht bewerkstelligen könne. Diese Menschen verharrten in einem „vorgelagerten Zwischenreich“"192. Hier sind sie sowohl von Gott als auch von ihren Mitmenschen getrennt.

Das „Chaos der Gegenwart“193, das in diesem Herausfallen aus angestammten Ordnungen zum Ausdruck kommt, lässt sich nach Kracauer als Resultat eines Prozesses begreifen. Nachdem der Mensch sich von Gott losgerissen und von der Vormundschaft der Kirche emanzipiert hat, taumelt er nun in eine existentielle Krise. Nach der aufklärerisch-vernünftigen und der romantisch-universellen Form ist das Ich im Kapitalismus zum „willkürhaften Zufallsgebilde“194 degeneriert. Diesem fragmentierten Ich entspricht eine auf es zurückgebogene, substantiell entleerte Wirklichkeit. ${ }^{195}$ Zur Zerrüttung des Ichs trugen die von Sigmund Freud diagnostizierten „drei schwere[n] Kränkungen“ bei, die die „Eigenliebe der Menschheit [...] von seiten der wissenschaftlichen Forschung erfahren hat" ${ }^{196}$. Freud bezieht sich dabei auf die kosmologische, biologische und psychologische Marginalisierung des Menschen. Eine der vielen Ergänzungen, die seine These seither erfahren hat, stammt von Stephen Jay Gould. Sie betrifft die „geologische Kränkung“ des Menschen durch die Entdeckung der Tiefenzeit. ${ }^{197}$ Die Erkenntnis, dass der Mensch in der Geschichte der Erde bloß ein winziger Punkt ist, forderte nicht nur die Zeitrechnung der Genesis heraus, ${ }^{198}$ sondern auch die teleologische Geschlossenheit geschichtsphilosophischer Gedankengebäude.

Dass sich für Kracauer mit solchen „historischen Ableitung[en]“ die Frage nach der Ursache für die geistige Entleerung zu Beginn des 20. Jahrhunderts al-

191 Kracauer, Die Wartenden, S. 107.

192 Kracauer, Die Wartenden, S. 108.

193 Kracauer, Die Wartenden, S. 107.

194 Kracauer, Die Wartenden, S. 107.

195 Vgl. Kracauer, Die Wartenden, S. 107.

196 Sigmund Freud, Eine Schwierigkeit der Psychoanalyse. In: Imago. Zeitschrift für Anwendung der Psychoanalyse auf die Geisteswissenschaften, 5, 1917, S. 1-7, hier S. 3.

197 Vgl. Stephen Jay Gould, Time’s Arrow - Time’s Cycle. Myth and Metaphor in the Discovery of Geological Time, London 1996, S. 1-2. Vgl. dazu auch die großangelegten Forschungen zur Poetik der Natur von Georg Braungart, etwa Georg Braungart, „Katastrophen kennt allein der Mensch, sofern er sie überlebt; die Natur kennt keine Katastrophen.“ Anthropozän, Kulturgeschichte der geologischen Kränkung und Globale Umweltethik. In: Ethik in den Wissenschaften. 1 Konzept - 25 Jahre - 50 Perspektiven, hg. von Regina Ammicht Quinn u. Thomas Potthast, Tübingen 2015, S. 321-328.

198 Vgl. Charles Coulston Gillispie, Genesis and Geology. A Study in the Relations of Scientific Thought, Natural Theology, and Social Opinion in Great Britain, 1790-1850, Cambridge 1996. 
lerdings keineswegs erledigt hat, weil sie keine Antworten „im metaphysischen Sinne“199 bereitstellten, macht deutlich, dass die diagnostizierte Misere bis in die Erforschung ihrer eigenen Ursachen ausstrahlt. Wenn in einer als heillos wahrgenommenen Welt nun Engel auftauchen, also Figuren einer klar definierten metaphysischen Ordnung, dann sind sie inmitten des allgemeinen Ordnungszerfalls in ihrer scheinbaren Unzeitgemäßheit erklärungsbedürftig. Mit der Vakanz eines numinosen Absoluten als ordnungsverbürgender Wahrheitsgrund wird die Referenz der Engel auf Gott prekär. Sie verweisen als Repräsentanten tendenziell auf eine Leerstelle, die entweder durch Hypostasierungen wie die des Künstlers, der Dingwelt oder des Unbewussten gefüllt werden kann oder die das angelische Modell vermittelnder Repräsentation selbst erodiert. Es stellt sich die Frage, ob der Engel in der Krise des göttlichen Mysteriums, das er bis dahin kommuniziert hat, überhaupt noch etwas mitzuteilen hat: Kann er in der Dynamik von Ent- und Resakralisierung die Abwesenheit göttlicher Eingebundenheit markieren und ein kommendes Heimfinden eschatologisch antizipieren oder hat er mit dem Wegfall des göttlichen Senders keine Funktion mehr und stellt in der Moderne nur noch ein atavistisches Irrlicht dar?

Der Philosoph Kurt Röttgers schreibt über den Engel im 20. Jahrhundert, es sei „zunehmend [...] seine eigentliche Botschaft, daß er kein Wesen mehr hat, sondern

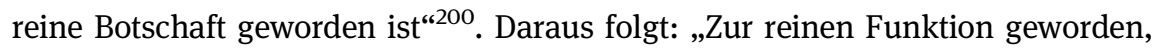
rein medial geworden, hört er auf, nützlicher Helfer beim Lösen des Problems der Metabasis zu sein, sondern ist eine der Erscheinungsweisen des Problems.“201 Gleicht man diesen theoretischen Befund mit Engelsfiguren in Texten der Moderne $\mathrm{ab}$, lässt sich allerdings der entgegengesetzte Vorgang beobachten. Die reine Medialität als Funktion, die Röttgers dem Engel in der Moderne attestiert, ist ja strukturell nichts anderes als seine einwandfrei vollzogene Tätigkeit als Bote. Wenn auch mit anderen Inhalten ausgestattet, würde der Engel so zur Vollendung dessen, was innerhalb eines monotheistischen Glaubenssystems postuliert, aber ständig durch angelische Störfeuer durchkreuzt wurde: Durchlässig für die Stimme und Präsenz Gottes oder moderner Substitute ist der Engel reines Medium ohne eigene ästhetische Dichte. Eine solche gewinnt er jedoch verstärkt in der Moderne. Denn die Krise der beiden Bezugspunkte Gott und Mensch führt dazu, dass das dritte Glied, der Engel, jenseits seiner medialen Funktion in der nunmehr brachliegenden oder wenigstens störanfälligen kommunikativen Vermittlung als eigenständiges Wesen in den Fokus rückt.

199 Kracauer, Die Wartenden, S. 107.

200 Röttgers, Die Physiologie der Engel, S. 49.

201 Röttgers, Die Physiologie der Engel, S. 49. 
Im Zuge der Aufklärung war das Christentum von kultisch-magischen Schlacken, unter die auch die hybriden Engel gerechnet wurden, befreit und auf seine Kompatibilität mit einer rationalisierten Ethik hin beschnitten worden. ${ }^{202}$ Das hatte zur Folge, dass die Weisungshoheit der Kirche als dominierende gesellschaftliche Institution zuerst theoretisch, dann immer mehr auch praktisch durch eine Pluralisierung von Deutungsangeboten unterhöhlt wurde. Mit dem Vormarsch eines protestantischen Innerlichkeitsdenkens und einer sich vom öffentlichen Kultus ins Private zurückziehenden Kommunikation der oder des Einzelnen mit Gott ${ }^{203}$ wurde auch die Vermittlungstätigkeit der Engel immer mehr zu einem verzichtbaren Beiwerk. Der viel diskutierte „Tod Gottes“ sorgt dann zu Beginn des 20. Jahrhunderts im Verbund mit einem verstärkten Interesse am Heiligen dafür, dass Engel als residuale numinose Figuren in den Fokus rücken, wenn es darum geht, unbegriffliche, transzendente Erfahrungsgehalte $\mathrm{zu}$ kommunizieren und die Hypotheken der Aufklärung kritisch zu hinterfragen. ${ }^{204}$ Die Angelophanie steht ein für eine epistemisch fragwürdige Erfahrung, die nicht quantifiziert und homogenisiert werden kann. Der Engel kommt plötzlich und verkörpert die Unverfügbarkeit des Draußen, die sich im Sinne von Horkheimers und Adornos Dialektik der Aufklärung (1944) nicht in die Immanenz positivistischer Welterfahrung bannen lässt. ${ }^{205}$ In dieser Logik ist der Engel als sakral-profane Figur kein nostalgischer Kitsch, sondern wirkt - so die These - in Texten der Moderne als Brennspiegel und Reflexionsfigur historischer Erschütterungserfahrungen ebenso wie zentraler Kontroversen in den Debatten um die Moderne.

202 Natürlich lässt sich das Denken der Aufklärung nicht allein auf die in Kapitel 2.1 referierte Position Kants reduzieren. Gísli Magnússon verweist in seiner Untersuchung etwa darauf, dass während der Aufklärung „die hermetische Esoterik untergründig weiterleben“ konnte (Gísli Magnússon, Dichtung als Erfahrungsmetaphysik. Esoterische und okkultistische Modernität bei R. M. Rilke, Würzburg 2009, S. 153).

203 Zur Ausdifferenzierung und Pluralisierung in der protestantischen Frömmigkeitskultur vgl. Justus H. Ulbricht, „Transzendentale Obdachlosigkeit“. Ästhetik, Religion und „neue soziale Bewegungen“ um 1900. In: Ästhetische und religiöse Erfahrungen der Jahrhundertwenden, Bd. 2, hg. von Wolfgang Braungart, Gotthard Fuchs u. Manfred Koch, Paderborn u. a. 1998, S. 47-67, hier S. 52-54.

204 Zur Konjunktur des Heiligen in der Modene vgl. Héctor Canal, Maik Neumann u. Caroline Sauter, Vorwort: Das Heilige (in) der Moderne. In: Das Heilige (in) der Moderne. Denkfiguren des Sakralen in Philosophie und Literatur des 20. Jahrhunderts, hg. von Héctor Canal, Maik Neumann u. Caroline Sauter, Bielefeld 2013, S. 7-12.

205 Vgl. Theodor W. Adorno u. Max Horkheimer, Dialektik der Aufklärung. In: Adorno, Gesammelte Schriften, Bd. 3, Frankfurt am Main 1981, S. 32. 
Insbesondere im Zusammenhang mit den Krisenerfahrungen der Moderne gewinnt der Engel als exilische Figur an Bedeutung. Wenn man mit Bernhard Greiner Exilliteratur bestimmt als eine „Literatur, die sich durch spezifische Strategien ausweist, die paradoxe Verschränkung von Entzug und Vergegenwärtigung im Akt der Repräsentation zu leisten und zu sichern“206, fällt die strukturelle Äquivalenz zur Engelsfigur und ihrer ästhetisch vermittelten Kommunikation eines Abwesenden ins Auge. Diese Affinität ist auch Teil der Vermittlungstätigkeit der Engel selbst, die im Aufschubs des Eschaton stattfindet, also in der Zeit nach der Vertreibung aus dem Paradies und vor dem Ende der irdischen Welt. Da seine mediale Tätigkeit nur im Exil, das heißt im Zustand einer Spaltung zwischen menschlicher und numinoser Sphäre, überhaupt von Nöten ist, trägt der Engel das Potential, die epochale Exilierung im 20. Jahrhundert zu illustrieren. Gleichzeitig vermag er als Figur einer überirdischen Verheißung aufzutreten, als die er Visionen einer besseren Zukunft kommuniziert. Aus diesem Grund wird der Engel vielfach für Reflexionen und Entwürfe neuer Ordnungen genutzt. So kann der Engel geschichtsphilosophische Visionen verbürgen, als Symbol einer übergeordneten Heimat oder Spender eines höheren Wissens fungieren und eine Sakralisierung und Erweiterung ästhetischer Erfahrung imaginativ stützen. Mit dem Engel, der das Versprechen birgt, die Qualitäten eines überirdischen Raums auf die Erde zu bringen, und der zugleich die Differenz gegenüber der historischen Zeit markiert, werden so grundsätzliche Aspekte des Verhältnisses von Modernität und metaphysischer Eingebundenheit beziehungsweise Exilierung berührt.

Ausgehend von den im Angelologie-Kapitel skizzierten strukturellen Affinitäten der Engel zu ordnungskonstitutiven, geschichtsphilosophischen und ästhetischen Fragestellungen der Moderne wird in den folgenden Kapiteln die spezifische Rolle moderner Angelophanien ausgelotet. Metaphysische wie soziale Exilzustände, die von realhistorischen Fluchtbewegungen im Zuge der beiden Weltkriege verstärkt und überlagert werden, sind ein zentraler Topos in den Werken von Rainer Maria Rilke, Walter Benjamin, Klaus Mann und Ilse Aichinger, der auf jeweils unterschiedliche Weise über den Engel verhandelt wird. Bei allen untersuchten Werken handelt es sich um ein Schreiben aus einer exilierten Position heraus. Diese entsteht sowohl aus dem modernen Entfremdungsdiskurs als auch durch individuelle biographische Entortungserfahrungen. Auch die Verschränkung von epochalen Exilzuständen einerseits und dem gattungstypologischen Zusammenhang von Reise-, Exil- und autobiographischer Literatur andererseits wird von dem

206 Bernhard Greiner, Re-Präsentation: Exil als Zeichenpraxis bei Anna Seghers. In: Placeless Topographies, hg. von Bernhard Greiner, Tübingen 2003, S. 161-174, hier S. 162. 
Engel zusammengehalten. ${ }^{207}$ Denn als geschichtsphilosophische Reflexionsfigur ist er Teil jener Erzählungen, die sich um die Trias von verlorenem Paradies, modernem Exil und zukünftiger elysischer Einheit ranken, während er in seiner Rolle als individueller Alter Ego an das Leben eines einzelnen Menschen gebunden ist, über das er gleichwohl in allen untersuchten Fällen hinausweist. Denn im Zuge der „Skelettierung des Humanum“208 im 20. Jahrhundert werden die Engel, die in Bezug auf den Menschen Alterität und Perfektibilität gleichermaßen figurieren, verstärkt für anthropologische Bilanzierungs- und Neubestimmungsansinnen fruchtbar gemacht.

$207 \mathrm{Zu}$ der gattungstypologischen Nähe von Reise-, Exil- und autobiographischer Literatur vgl. Xenia Wotschal, Schreiben und Reisen über Gattungsgrenzen hinweg. Gattungsmischung und -bildung bei Rolf Dieter Brinkmann, Ilse Aichinger und Herta Müller, Heidelberg 2018, S. 60 .

208 Fritz J. Raddatz, Rainer Maria Rilke. Überzähliges Dasein. Eine Biographie, Hamburg 2016, S. 109. 